IZA DP No. 9499

The Effect of Linguistic Proximity on the Occupational Assimilation of Immigrant Men in Canada

Alícia Adserà

Ana Ferrer

November 2015

Forschungsinstitut zur Zukunft der Arbeit Institute for the Study of Labor 


\title{
The Effect of Linguistic Proximity on the Occupational Assimilation of Immigrant Men in Canada
}

\author{
Alícia Adserà \\ Princeton University \\ and IZA \\ Ana Ferrer \\ University of Waterloo \\ Discussion Paper No. 9499 \\ November 2015 \\ IZA \\ P.O. Box 7240 \\ 53072 Bonn \\ Germany \\ Phone: +49-228-3894-0 \\ Fax: +49-228-3894-180 \\ E-mail: iza@iza.org
}

Any opinions expressed here are those of the author(s) and not those of IZA. Research published in this series may include views on policy, but the institute itself takes no institutional policy positions. The IZA research network is committed to the IZA Guiding Principles of Research Integrity.

The Institute for the Study of Labor (IZA) in Bonn is a local and virtual international research center and a place of communication between science, politics and business. IZA is an independent nonprofit organization supported by Deutsche Post Foundation. The center is associated with the University of Bonn and offers a stimulating research environment through its international network, workshops and conferences, data service, project support, research visits and doctoral program. IZA engages in (i) original and internationally competitive research in all fields of labor economics, (ii) development of policy concepts, and (iii) dissemination of research results and concepts to the interested public.

IZA Discussion Papers often represent preliminary work and are circulated to encourage discussion. Citation of such a paper should account for its provisional character. A revised version may be available directly from the author. 


\section{ABSTRACT \\ The Effect of Linguistic Proximity on the Occupational Assimilation of Immigrant Men in Canada*}

This paper contributes to the analysis of the integration of immigrants in the Canadian labour market by focusing in two relatively new dimensions. We combine the large samples of the restricted version of the Canadian Census (1991-2006) with both a new measure of linguistic proximity of the immigrant's mother tongue to that of the destination country, and with information of the occupational skills embodied in the jobs immigrants hold. This allows us to assess the role that language plays in the labour market performance of immigrants and to better study their career progression relative to the native born. Weekly wage differences between immigrants and the native born are driven mostly by penalties associated with immigrants' lower returns to social skills, but not to analytical or manual skills. Interestingly, low linguistic proximity between origin and destination language imposes larger wage penalties to the university-educated, and significantly affects the status of the jobs they hold. The influence of linguistic proximity on the skill content of jobs immigrants hold over time also varies by the educational level of the migrant. We also show that immigrants settling in Quebec and whose mother tongue is close to French have similar or better labour market outcomes (relative to native-born residents in Quebec) than immigrants with close linguistic proximity to English settling outside Quebec (relative to native born residents in the rest of Canada). However, since wages in Quebec are lower than elsewhere, immigrants in Quebec earn less in absolute terms than those residing elsewhere.

JEL Classification: F22, J24, J31, J5

Keywords: migration, occupational skills, linguistic ability, wage assimilation, linguistic proximity

Corresponding author:

Alícia Adserà

Woodrow Wilson School

Princeton University

347 Wallace Hall

Princeton, NJ 08544

USA

E-mail: adsera@princeton.edu

\footnotetext{
* The analysis was conducted at the South Western Ontario RDC which is part of the Canadian Research Data Centre Network (CRDCN). The services and activities provided by the CRDCN are made possible by the financial or in-kind support of the SSHRC, the CIHR, the CFI, Statistics Canada and participating universities whose support is gratefully acknowledged. The views expressed in this paper do not necessarily represent the CRDCN's or that of its partners'.
} 


\section{Introduction}

For Western economies that rely on large influxes of immigrants as a way of encouraging economic growth and demographic sustainability, successful immigrant assimilation is of capital importance. Previous research highlights the influence of linguistic ability - either actual proficiency or an indicator of how easy would be to learn the host country language - as a key determinant of immigrant economic success. In general, we expect immigrants with greater linguistic ability to integrate faster in the labour market and have a larger capacity to transfer human capital to the host country than those with lesser ability. To obtain some measure of how much linguistic ability matters should be of particular interest for countries that have based their immigration policies on attracting high skilled immigrants such as Australia and Canada, and for those contemplating such policies in the near future (OECD, 2014).

In this paper we use a new measure of linguistic proximity to assess whether language ability greatly influences the wage assimilation and career progression of immigrants to Canada. Specifically, we explore whether linguistic ability affects the returns to human capital and whether it enables faster job integration, measured by the change in skills associated with the jobs held by migrants. We use Canadian bilingualism to further test whether linguistic proximity makes a difference in the process of integration. By comparing the performance of immigrants with close linguistic proximity to French (English) settling in Quebec versus in the rest of Canada, we hope to offer additional evidence on the impact of language fluency on economic assimilation.

Theories of immigrant assimilation consider that, upon arrival, the new immigrants' lack of country specific human capital (language fluency, institutional knowledge, recognized credentials) will cause a depreciation of the human capital they bring into the country. This depreciation is in part responsible for the lower earnings of migrants immediately after arrival when compared to similar native-born workers. Economic theory predicts that, with time in the country, the acquisition of country-specific skills will boost immigrant's earnings towards those of similar native-born workers. A long tradition of academic and non-academic studies documents this phenomenon using different measures of labour market performance (Chiswick, 1978 and 1986; Borjas 1985). Since the 1990s, these studies report that new cohorts of immigrants to the US and Canada have experienced a significant deterioration in their economic well-being relative to previous arrival cohorts (Borjas 1995; Aydemir and Skaterud 2005; Antecol et al, 2006). The drop in earnings and employment has largely been attributed to changes in immigrant's background (Friedberg, 2000; Bratsberg and Raaum, 2004; Borjas (2013),). More specifically, language ability has been 
underscored in different studies as one of the main determinants of successful integration (Borjas, 2013; Bleakley and Chin, 2004; Chiswick et al., 2005).

Both fluency in the language of the destination country and the ability to learn it quickly are likely to influence immigrant's labor market success in destination countries and whether or not poor initial outcomes change with time in the country. A long established literature investigates the effect of linguistic ability on the social and economic outcomes of immigrants in the US (Kossoudji, 1988: Chiswick and Miller, 2002 and 2010; Bleakley and Chin, 2004 and 2010), Europe (Dustmann, 1994; Dustmann and van Soest, 2001 and 2002; and Dustmann and Fabbri, 2003) and Australia (Chiswick and Miller, 2007).

We build on this literature to assess the influence of linguistic ability on the occupational assimilation of immigrant men to Canada. This is of particular relevance in the Canadian case where immigration policy has targeted educated immigrants for quite some time. Most immigrants in the relevant period we analyze here entered Canada as economic immigrants and are assessed through a points system. This points system was introduced in the mid-1960s to respond to short-term labour market needs: points were assigned to specific occupations. In the early 1990s the system was adjusted to increase the importance of general human capital characteristics, notably education, in the selection process. In 2002, the Immigration and Refugee Protection Act (IRPA) continued to stress the "human capital" model of immigration (for a more thorough description of the immigration system, see Ferrer et al. (2014) and references therein). In this context, any increase in of immigrant-native wage differences among recent cohorts - once education and other observable characteristics have been accounted for - would be even more puzzling.

Although language ability has, for the most part, always been embedded in the points system, poor linguistic ability has often been invoked as one of the reasons behind observed differences in outcomes between immigrant and native-born workers. ${ }^{1}$ However, the effect of linguistic fluency on labour market performance of Canadian immigrants has been less explored because the Canadian census lacks a proper measure of linguistic ability. Studies that have addressed the effect of language proficiency on labour market assimilation of Canadian immigrants typically rely on self-

\footnotetext{
${ }^{1}$ Pre-IRPA, proof of language ability was subject to interviewer's approval. Only after the introduction of IRPA in 2002, aapplicants must submit either written evidence demonstrating their language ability in Canada's official languages or provide language test results from an approved organization or institution, although the test per se is not mandatory (Begin et al., 2010).
} 
reported measures. ${ }^{2}$ A distinctive feature of this study is the use of a measure of linguistic proximity (LP), to approximate for linguistic ability, which allows us to uncover richer patterns of the role of language on the assimilation of Canadian immigrants than can be derived from self-reported measures. ${ }^{3}$

Further, language training policies for recent immigrant are broadly implemented on the basis of facilitating immigrant's integration in their new social and cultural environment. The extent to which they could also facilitate labour market integration into better jobs has not been explored in depth. Notable exceptions are the study of Israeli immigrants by Berman et al. (2003) showing the existence of complementarities between language proficiency and occupations in a limited set of occupations, and that of Imai et al. (2014) exploring the role of language proficiency in the transfer of skills upon immigration. To this end, besides traditional labour market outcomes such as earnings and participation, this paper focuses in the occupational skills required in each job. This is a relatively new feature in the study of job transitions pioneered by Autor (2013), and one that is particularly relevant to understand the dynamics of immigrant assimilation. The nature of the work performed in a particular job is a dimension along which the labour force outcomes of immigrant and native-born workers are likely to differ. If immigrants have relatively more difficulty in finding jobs that match their skills, due to lack of credentials or experience in the destination market, they may end up in lower status or more unskilled jobs than similar native born. The extent to which this under-placement becomes a permanent as opposed to a temporary situation is a matter of great policy concern. The ability to analyze these dynamics only with standard measures of occupational category may be limited. Considering broad measures of occupational status - such as blue/white collar or managerial/non-managerial jobs - may miss a substantial part of the heterogeneity within occupational status, but including too finely detailed job classifications --such as 4-digit level SOC occupations - is impractical. Autor and Handel (2013)'s use the detailed information contained in occupation databases - either the Dictionary of Occupational Titles (DOT) or the Occupational Information Network (O*NET) - to derive a small set of fundamental skill requirements for each job to be used in the analysis. These measures have the advantage of being limited in range, but to account for variation across very detailed occupational classifications.

\footnotetext{
${ }^{2}$ See an early study by Chiswick and Miller (2003) which uses 1991 public Census data file and Imai et al., (2014) which uses the Longitudinal Survey of Immigrants to Canada).

${ }^{3}$ Recent studies (Chiswick and Miller, 2005; Isphording and Otten, 2011) show that it is easier for a foreigner to acquire a language if her native language is linguistically close to the language to be learned.
} 
This paper contributes to the literature by combining the large samples of the confidential Census files with information on both the occupational skills required in each job and with a measure of linguistic proximity between origin and destination languages. This allows us to assess whether the skills required by jobs immigrants hold are influenced by the linguistic proximity between the languages of the source and host countries. Of particular interest is whether linguistic proximity is more important in obtaining and/or moving to jobs that require specific social or communication job-skills, rather than to jobs requiring specific analytical or strength skills. Further, given the linguistic diversity within Canada, we explore whether assimilation (both in skills employed and in weekly wages) varies with the degree of linguistic proximity between immigrant's mother tongue to either English or French.

Our results show that linguistic proximity affects the returns to human capital and the skills required in jobs held by immigrant men. We find that wage penalties are mostly associated with lower returns to social skills, rather than to other skills, and that these differences exist even for immigrants from English speaking countries. While LP substantially affects the level of returns at arrival (as in Imai et al., 2014), we do not find strong evidence that it influences the rate at which migrants converge toward wage parity with native-born workers in the medium to long term. Similarly, LP is associated with the skills required in the jobs immigrants hold, but it does not seem to influence the rate at which they move to jobs with higher required skills (or move into better jobs). Interestingly, linguistic proximity imposes larger wage penalties to the university-educated, and significantly affects the status of the jobs they hold.

We also show that immigrants settling in Quebec and whose mother tongue is close to French have similar or better labour market outcomes (relative to native-born residents in Quebec) than immigrants with close linguistic proximity to English settling outside Quebec (relative to native born residents in the rest of Canada). However, since wages in Quebec are lower than in the rest of Canada, immigrants in Quebec earn less in absolute terms than those residing elsewhere.

The next section describes the methodology and data used in the analysis. Sections 3 and 4 presents the results for weekly wages and skills respectively and section 5 concludes.

\section{Data}

\subsection{Sample description}

Data comes from the restricted files Canadian Census (1991, 1996, 2001 and 2006). The confidential files offer detailed information on individual fertility, occupation, country of birth, year 
of arrival and mother tongue for $20 \%$ of the individuals. The long form Canadian Census, that contains the confidential files, was collected for the last time in 2006.

Our sample includes men aged 18 to 60 and excludes aboriginal individuals. In order to reduce computing time to a reasonable length, we select all immigrants (who arrived at age 18 or older) plus a 25 percent random sample of Canadian born individuals from each census. Observations are weighted accordingly. We only study immigrants who arrived as adults because the behaviour and the language ability of immigrants arriving as children or teens is quite different from that of those arriving as adults (Shaafsma and Sweetman, 2001). For individuals currently working, information about the skills required to perform the job - form O*Net database - is linked to their employment record through 4-digit occupational codes present in both surveys. In addition, each immigrant record is further linked to information about his country of birth at the time of migration, obtained from Frank and Hou (2013), including GDP per capita, fraction of individuals with higher education and female labour force participation.

\subsection{Wages and Skill-requirements}

The Census collects information on the wages and weeks worked the previous year; however information on hours of work is collected for the census reference week. Since it is difficult to obtain a reliable measure of hourly wages, we follow other Canadian studies and use weekly wages as our first measure of labour market performance.

As mentioned above, most job changes may not result in shifts in occupational category, particularly when measured broadly, but they may involve substantial adjustments in the skills required in the new position. In order to capture variation across narrowly defined occupations without overwhelming estimation procedures, Autor and Handel (2013) recommend the use of detailed information contained in occupation databases - either the Dictionary of Occupational Titles (DOT) or the Occupational Information Network (O*NET) - to derive a small set of fundamental skill requirements for each job. Imai et al. (2011) summarize the detailed information in the $\mathrm{O}^{*}$ NET by constructing a low-dimensional vector of occupational characteristics in Canada using Principal Component Analysis (PCA). The outcome is a vector of skill requirements that are limited in range, but account for variation in very detailed occupational classifications at the 4-digit occupational category.

We use Imai et al. (2014) skill index to make our results consistent with others that look into the occupational mobility of Canadian immigrants. Their factor analysis employs the distribution 
of skills of the Canadian working population as weights, which makes the indexes easily interpretable: one unit of the skill score (with mean zero) can be interpreted as one standard deviation in the skill distribution of the Canadian population. ${ }^{4}$ They produce two indexes for cognitive skills (social and analytical) and three indexes for manual skills (fine motor skills, physical strength, and visual skills). This classification differs from that employed by those who study the routine/non-routine nature of the jobs (Autor and Dorn, 2013; Warman and Worswick, 2015) to understand the effect of skill biased technological change on wage inequality. We abstract from this distinction to focus on the more general notion of manual and non-manual skills. Note that the measure of skills we use refers to the demand side of the market, i.e. to the skills involved in performing each job, not the actual skills of the worker. A positive index indicates that a job requires, for example, either more physical strength or analytical demands than the job held by the average worker.

The correlation between the skills we consider is substantial. Strength skills are positively and significantly correlated with motor and visual skills, and negatively correlated with analytical and social skills (see Table 4B in the Appendix). The latter two are positively and strongly correlated between themselves. The wage models we estimate include all five measures of skills. However, when discussing wage results and also when assessing job integration, we focus on the two cognitive skills, social and analytical, and the manual skill "strength". Given the emphasis of Canadian immigration policy on skilled immigration, we are most interested in analyzing whether immigrants integrate in high status jobs, which typically require high levels of social and analytical skills and low levels of strength.

\subsection{Linguistic Proximity}

As suggested by previous research, both fluency in the language of the destination country and the ability to learn it quickly will influence an immigrant's success in the destination labor market (Bleakley and Chin 2004; Chiswick and Miller 2002, 2010; Dustmann and van Soest 2002). Hence, variation in linguistic proximity to the local language can be used to approximate ease of access to labor market opportunities. Given the limited information on language available in the Canadian census, we use a measure of linguistic proximity between two countries developed in Adserà and Pytliková (2015) and based on information from the encyclopaedia of languages

\footnotetext{
${ }^{4}$ In the PCA, factor loadings are calculated so that variation of the data explained by the constructed variable is maximized. A detailed description of the procedure can be found in Imai et al. (2011).
} 
Ethnologue (Lewis, 2009) to capture this variation. We create a set of indicators that vary according to how many levels of the linguistic family tree the languages of both the destination and the source country share. Thus, our first indicator variable denotes that two languages do not share any level of the linguistic tree (Chinese and English); the second one that two languages are only related at the most aggregated linguistic tree level (Indo-European languages); the third dummy that two languages belong to the same first and second-level of the linguistic tree (Germanic languages); the fourth dummy that two languages share up to the third linguistic tree level (Romance languages); and the fifth dummy that both languages share up to four levels (Danish, Norwegian and Swedish). One additional indicator equals 1 if both languages are the same (or share the fifth or higher levels). This set of variables provides a far more detailed metric of proximity between any pair of languages than the standard indicator for common language used in most of the literature. It better captures heterogeneity of origins that a self-reported variable for language fluency employed by Imai et al. (2011) that classifies immigrants between those who speak "very good" or "poor to moderate" English. In their paper they use it to explore the short term effects of language ability on occupational mobility during the first five years after arrival to Canada. ${ }^{5}$

We match these measures to individuals through the variable "place of birth", that indicates the person's country of birth contained in the Canadian census.

In absence of an objective measure of performance, such as an exam, the quality of the proxy employed to measure linguistic fluency is important. Even though our measures are likely to be a good approximation of linguistic proximity for the average individual in the country, immigrants are likely a selected group of the population. They could arrive as refugees escaping economic or political hardship, as economic immigrants seeking better opportunities or as relatives of settled immigrants. To provide a more robust assessment of the role of linguistic ability, we employ several metrics to construct different sets of indicators of linguistic proximity (LP) to proxy language fluency. A first metric, the broadest one, measures of the minimum distance between either English or French (the two official and most widely-spoken languages in Canada) and any of the official plus the two most widely-spoken languages in the country of origin of the immigrant. This metric is denoted as "Any official/major". A second metric considers the minimum distance between the

\footnotetext{
${ }^{5}$ They use the Longitudinal Survey of Immigrant to Canada (LSIC) which follows the immigrant cohort landing in 2001 through their first 5 years in Canada. This data set is extremely rich in terms of information. However, it is constrained in terms of the sample (only one immigrant cohort, and no native born sample) and the timing considered (4 years after migration).
} 
most used language at origin and the most used language at destination (English), which is denoted as "most- used". ${ }^{6}$ Note that under this metric we do not have an indicator for the $4^{\text {th }}$-level linguistic proximity because no migrant origin language shares three branches with English. For the "Any official/major" metric, Romance languages share up to the $4^{\text {th }}$ level with French.

The first metric produces the most flexible measure of linguistic proximity, as it encompasses any potential link between the languages in the two countries. If immigrants are a positively (in terms of ability) selected group of the population, they are more likely to be familiar with the host country language - even if it is not their usual language - if, for example, they have studied it in school as one of their country's official languages Thus, the broader measure will be more likely to accurately reflect their linguistic ability. However, the second measure likely indicates more precisely (at least statistically) the linguistic ability of the average citizen in the country, as it picks up proximity between the language most commonly used at origin and English. To the extent that positive selection is moderate, this measure might be more appropriate. Note also that "most-used" measures proximity to English only. Hence its accuracy might be affected by immigrant's settlement choice between provinces with either large French or English-speaking populations. In the paper we estimate our models with both measures. To illustrate the differences in the measures, consider some countries where English or French are either an official language or among the two most-used languages: India, Philippines, Kenya, Cameroon or Madagascar as well as the US, UK or France. In this group, only the US and the UK are countries where the most used language is English.

In robustness analysis we employ a number of alternative measures of linguistic distance such as the Levenshtein index (created at the Max Planck institute) which relies on phonetic dissimilarity of the 40 most common words between each pair of all world languages, and the Dyen index based on the similarity between samples of words only among Indo-European languages.

\subsection{Descriptive Statistics}

Summary statistics are presented in Table 1 . Immigrants are generally older than the native born, and more likely to have university education than natives. Immigrant men hold jobs that require,

\footnotetext{
${ }^{6}$ We also consider a third metric that measures the distance between the first official language at origin and destination, denoted "first official". Compared to the most used language, this metric involves a major change for immigrants from South Africa, Jamaica and Guyana, who do not share any branch with English under the most used criteria, but share 3 branches (South Africa) or use the same language (Jamaica and Guyana) under the first official language metric. However, since there are not significant changes in the regressions when using either metric, we report results using the most used language to keep the paper at a reasonable length.
} 
on average, similar interpersonal skills, higher analytical skills and less strength skills than the average Canadian-born males. A look at the full distribution of skills (Figure 1) unveils that immigrant men work in jobs that are heavily concentrated in the lower tail of the strength distribution and that the distribution of their required analytical and social skills is flatter than that of the native born, with lower fractions in the middle and lower ranges of the distribution.

Regarding LP, Table 1 shows the fraction of immigrants that fall into each category for both metrics. The differences between the two measures are significant. When measured by the most used language, around 44\% of immigrant men come from a country where the most widely-spoken language has no common branch with English. The corresponding share is only 18\% when employing the broadest measure. To facilitate the discussion, we refer the reader to Table 2, where we report the main source countries in each category of LP according to the any official/major metric (column 1) and the most-used metric (column 2). The main source countries where the mostused official language has not branch in common with English are China, Philippines, Pakistan and Korea, those where the first official language is Arab (Egypt, United Arab Emirates) and most African countries. The majority of these countries still exhibit the lowest linguistic proximity (no common branch) when using the any official/major metric instead, with the notable exception of Philippines and Pakistan. Countries sharing one branch in common comprise $16 \%$ (37\%) of immigrants when measuring any official/major (most-used) language. The difference between the two metrics is mainly due to India, where English is one of the official languages, but where the most common language used is Hindi (that shares only one branch with English). Northern European countries (Denmark, Iceland, Norway and Sweden) share two levels of the linguistic tree in common with English or French (any official/major metric) or English only (most-used metric). This group amounts to a very small fraction of immigrants to Canada, $1 \%$ and $0.004 \%$ respectively. Countries with three linguistic branches in common with English (any official/major or most-used metric) are those of Germanic origin (Switzerland, Germany, Belgium, The Netherlands and their colonies). This is a relatively small group accounting only for 5\% of immigrants. The main difference between the two groups is the presence of Romania under the any official/major metric. Finally, the main countries with the same language, English or French, (any official/major metric) are India, US, UK, Ireland, France, as well as some former African or Asian colonies. These amount to $43 \%$ of all immigrants. However this fraction shrinks sharply (14\%) when considering the proximity to English only under the most-used metric, mainly as a results of the change in classification of India and the Philippines. 
The last column of Table 2 presents the main source countries by linguistic proximity to French for the most-used metric. France is the major origin with the same language. Countries with romance languages that share up to four linguistic branches with French, such as Italy and Portugal, are the largest senders in this group. The list of countries without any linguistic connection to French is essentially the same as that for English in column (2). Compared to column (2), the UK and the Netherlands are now included to the group with only one branch in common with French and France is out. No countries share only two levels of the tree with French.

Finally, Table 1 shows that the Levenshtein index (that ranges from 0 for equal languages to around 106 in the sample) has an average of 50 when using the any official/major metric, but of 80 when considering the most-used language.

\section{Regression results}

\subsection{Wages and linguistic proximity}

Our basic specification is a common Mincer earnings equation augmented to consider both the role of skills required by jobs and linguistic proximity.

$$
\log \left(w_{i}\right)=X_{i} \beta_{1}+\beta_{2} \sum_{s} \text { skill }_{S}+\beta_{3} \sum_{l=0}^{5} L_{l}+\beta_{4} \sum_{t=90}^{00} \text { year }_{t}+\epsilon_{t}
$$

The dependent variable $\left(\log w_{i}\right)$ is a measure of the weekly wages of individual $i$; $X_{j}$ is a vector of individual demographic characteristics, including characteristics of the country of birth. Skills denotes the indexes for the 5 job-required-skills ( $s$ = motor, visual, strength, analytical and social), while $L_{i}$ are six dummy indicators of immigrant linguistic proximity ranging from "no linguistic proximity" to an indicator for "same language". We include a set of year dummies, $t=1990,1995$, 2000 and 2005, to control for the year when weekly wages of the individual were measured. The vector of individual demographic characteristics, $X_{j}$, contains marital status, location (province, and Census Metropolitan Area), education, experience and experience squared, and the GDP per capita at the country of origin (measured when the immigrant immigrated). The $\beta$ 's are the vectors of estimated coefficients.

Table 3 reports estimates from equation (1), that show the difference in log weekly wages between immigrant and similar native-born individuals, when controlling for skills and linguistic proximity. Regressions employ any official/major language in columns 1 through 3 and most-used language in columns 4 through 6 . Our goal is to assess whether there are strong correlations between different levels of linguistic ability and weekly wages in the data after controlling for basic 
covariates. The models do not include years since migration (ysm) since, rather than focusing on the differences of wages at entry by linguistic proximity, we aim in this initial specification to capture average differences across groups. ${ }^{7}$ We explore variation with time in Canada with a fully flexible specification in models below. To (partially) disentangle the effect of language from that of area of origin, some models also include the place of birth of the immigrant (columns 2 and 5).

Not surprisingly, jobs requiring either high levels of analytical skills or low levels of strength are associated with higher weekly wages (respectively around $16 \%$ and $8 \%$ higher per one standard deviation difference in skill requirements). Social skills seem to play a small role: one additional standard deviation in social skills above those of the mean worker increases weekly wages by only $1 \%$.

As expected, immigrants with closer linguistic proximity have higher weekly wages than those with lower proximity. Column 1 shows that, when using the any official/major metric, immigrants whose languages share no branch in common with either English or French receive weekly wages around 32\% lower than similar native-born workers. The wage penalty gradually diminishes as languages become closer to English/French with the exception of immigrants from countries with a $2^{\text {nd }}$ level of linguistic proximity (mostly Nordic languages) who experience the least penalties (around 9\%), even lower than those who share the same language (18\%). Those who share four branches experience penalties (17\%) similar to those with same language. Note that these estimated differentials are net of the level of development in the country of origin (accounted by the GDP per capita at the time of migration).

Results are very similar when using the most used metric in column (4). ${ }^{8}$ The main difference is that under the most used metric the wage penalty to those for whom the most commonly used language is English is very small (6\%) due to the more restricted group of countries included in the group. This suggests that the any official/major metric may indeed be a nosier measure of linguistic ability.

Linguistic proximity can be associated with other traits such as ethnicity, religion, the quality of educational institutions in the country of origin, or even the actual level of exposure to the foreign

\footnotetext{
${ }^{7}$ When we introduce ysm in specifications similar to those in columns (2) and (5) in Table 3, we obtain estimates for the value of a given level of LP at entry that are consistent with those shown in table 3 . These estimates are available upon request

${ }^{8}$ Note that while those with a Romance language (such as Spanish, Italian, or Portuguese) had a $4^{\text {th }}$ level LP when using “Any official/Major" due to their closeness to French, they only share one branch with English. As explained before, there is no estimate for the $4^{\text {th }}$ level when using the most used metric
} 
language through mass media. When we introduce controls for place of birth (POB) in columns (2) and (5) the estimated wage differentials shrink substantially for some groups, regardless of the metric used, suggesting that language partially picks up the effect of other country characteristics. In particular, the wage differential for immigrants whose language has no connection to Canadian languages decreases from $32 \%$ to $16 \%$ with the any official/major metric and from $34 \%$ to $19 \%$ with the most used metric. The gaps also closes considerably for those with a $4^{\text {th }}$ level of LP or with the same language. Further, immigrants with a $2^{\text {nd }}$ level LP (Nordic countries) no longer display significant wage gaps with the native born. ${ }^{9}$

Finally, columns 3 and 6 in table 3 present similar results using the Levenshtein index of linguistic distance as an alternative proxy for linguistic proximity. The coefficient for the immigrant indicator measures the wage gap between migrants with no distance to the Canadian language (Levenshtein=0) and native born. The estimated coefficient for the Levenshtein index (negative because it measures distance) produces results that are in line with those presented with the indicators derived from the Adserà and Pytliková index. Results in column (3) imply that, when using any official/major metric, weekly wages of an English or French speaker are $16 \%$ lower than those of a native born. An immigrant with an average Levenshtein score (50) faces an additional 5\% penalty. In column 6, using the most used metric, weekly wages for English-speaking immigrants are 5\% lower than those of natives. Weekly wages of an immigrant with the average linguistic distance (score 80) are around 21\% lower than those of the immigrant with no distance (and 26\% lower than natives). ${ }^{10}$

\subsection{Does linguistic proximity affect the returns to some skills more than others?}

Given the emphasis of Canadian policy during the 1990s and early 2000s on selecting immigrants with high levels of human capital, in particular high levels of formal education, we ponder whether or not the transfer of skills embodied in formal education depends greatly on the degree of linguistic proximity.

First, we consider the association between weekly wages and both LP indicators and skills required by jobs for the subsample of university-educated individuals (Table $1 \mathrm{~A}$ in the appendix) using the same methodology as in Table 3. The basic patterns are consistent with those in Table 3.

\footnotetext{
${ }^{9}$ This result is driven by a combination of two factors: first, the small number of immigrants in this category, and second the fact that more than $80 \%$ of the population in Scandinavian countries speaks fluent English (see also footnote 14).

${ }^{10}$ Estimates with Dyen index for indo-european languages produced similar results available upon request.
} 
The most significant differences with respect to the whole-sample estimates are a higher return associated with social and analytical skills, and somewhat smaller wage gaps of university-educated immigrants with high levels of LP relative to university-educated natives.

Next, to further explore whether LP affects the return to immigrant's formal education, we introduce an interaction between university education and LP in the basic model

$$
\log \left(w_{i}\right)=X_{i} \beta_{1}+\beta_{2} \sum_{s} \text { skill }_{S}+\beta_{3} \sum_{l=0}^{5} \text { univ } * L_{l}+\beta_{4} \sum_{t=90}^{00} \text { year }_{t}+\epsilon_{i}
$$

where univ is an indicator for university education.

Results in Table 4 display estimated weekly wages for different levels of LP and formal education relative to those of native born men with no university education. Linguistic proximity affects returns to education. In particular, penalties for low linguistic proximity are larger when comparing university-educated immigrants and similarly-educated native-born workers than between those without university education. In Table 4, Panel A (any official/major), wages for non-university educated immigrants with no linguistic connexion to Canadian languages are, on average, $10 \%$ lower than those of similarly-educated natives, but among university-educated the difference rises to $20 \%$. University-educated natives make $65 \%$ more than non-university educated natives, and immigrants only 45\% more. In Panel B (most-used) there are no significant wage differences between natives and immigrants who share the same language for any level of education. The gap for immigrants with no linguistic connexion to Canadian languages stands at $18 \%$ for the non-university educated and $25 \%$ for those with a college degree.

Besides the return to formal education, linguistic proximity also likely affects the return to the specific set of skills required by the jobs immigrants hold. It is possible that LP matters more in jobs requiring mostly social skills rather than physical strength. To explore this, we add an interaction between LP and skills in the wage equation

$$
\log \left(w_{i}\right)=X_{i} \beta_{1}+\beta_{2} \sum_{s} \text { skill }_{S}+\beta_{3} \sum_{l=0}^{5} l_{l}+\beta_{4} \sum_{s} \sum_{l=0}^{5} \text { skill } s * L_{l}+\beta_{5} \sum_{t=90}^{00} \text { year }_{t}+\epsilon_{i}
$$

where $\beta_{2}$ is a vector measuring the returns for one additional standard deviation of each skill for the native born (relative to the average worker), $\beta_{3}$ measures the returns to immigrants with different levels of linguistic proximity and same skills than the average worker (relative to the average worker), and $\beta_{4}$ measures the joint effect of skills and linguistic proximity on wages of immigrants (relative to native born with the same levels of skills). 
Table 5 summarizes the effect of one standard deviation (SD) increase in the level of skills required by a job on the weekly wages of different types of workers, relative to the average worker. The first column shows returns to the native born in reference to the average worker. The other columns refer to immigrants with different degrees of linguistic proximity, as measured by the any official/major metric (Panel A) or the most-used metric (Panel B), relative to a native born with the same skill requirements. For instance, in panel A, a native born whose job requires social skills one SD above the mean earns $2 \%$ more than the average worker. An immigrant with an official Canadian language and social skills one SD above the average worker earns 9\% less than a native born with the same level of skills (and 7\% less than the average native worker). ${ }^{11}$ The penalty for the same migrant in Panel B is only 6\%. Interestingly there is no significant wage difference between these immigrants and natives when working in jobs requiring one SD above the mean in strength or analytical skills (in both Panels A and B).

Penalties to immigrants with low linguistic proximity to Canadian languages are also larger for social skills than for strength or analytical skills. Weekly wages of immigrants sharing no common branch with languages in Canada (under either metric) are around 28-31\% lower than those of a native born whenever both work in a job requiring one SD above the mean social skills. Wages of the same immigrant relative to a native born whenever both of them work in jobs requiring one SD of either lower strength or higher analytical skills are, respectively, only $20 \%$ and $11 \%$ lower in Panel A (or 16\% and 12\% lower in Panel B). A somewhat surprising finding is the relatively good performance of immigrants with no linguistic proximity in terms of analytical skills.

Figure 2 shows the predicted weekly wages of immigrants with different LP (using the mostused metric) and levels of either social or analytical skills relative to the average worker (represented by the $X$-axis). We focus on the levels of LP proximity that include the largest shares of immigrants (denoted by LP $=$ None, $L P=1$ and $L P=$ Same). Figure 2 also includes the relative wages of a native-born worker as he/she uses more or less social or analytical skills than the average worker. Overall, working in jobs with increasing analytical skills has a strong positive association with wages, and most immigrants surpass the average native-born wage if in jobs requiring between zero and one standard deviation of analytical skills. Immigrants whose languages do not share any common branch with English achieve wage parity with the average Canadian-born worker in jobs

\footnotetext{
11 These numbers can be calculated from Appendix Table 2 (that shows estimates of $\beta_{2}, \beta_{3}$ and $\beta_{4}$ in equation 4) as the sum of the coefficient for "same language" (-0.06) and that of the interaction between social skill and "same language" (-0.04). Minor differences may exist due to rounding.
} 
that require around 0.75 SD more analytical skills than the average. Those coming from a country where English is the most used language achieve native average wages when working in jobs requiring $0.25 \mathrm{SD}$ above the average. In jobs at the highest level of analytical skill requirement, (2 SD above the average job) the wages of native born, and immigrants are quite similar. The outlook is quite different regarding social skills. Those with low LP, working in jobs requiring low social skills, have wages around the average and close to those of the native-born in these jobs. However, wage differences increase as we consider jobs with higher skill requirements. Those of Englishspeaking origins have wages close to those of the native born in jobs with the same social skills requirements.

There are two plausible explanations for the wage convergence in jobs requiring high levels of analytical skills by those with no language proximity. One is that immigrants in this language category (mostly Chinese) are actually quite proficient in English. However, this is unlikely since the relative wages of this group decline substantially as jobs require more social skills. An alternative explanation is that there is a niche in jobs requiring high levels of analytical skills but relatively low levels of social skills where these immigrants fit quite naturally. Although the level of correlation between social and analytical skills is quite high (0.88) such niches may exist for certain subgroups of the population.

Overall we find that linguistic ability is important in determining the rewards to different skills. Although our unidimensional skill measures cannot asses the importance of the different skill-packages associated with each job, it is useful to disentangle their separate effects. ${ }^{12}$ To attempt to capture variation across the different dimensions considered here we construct a composite index that combines them. We follow Faged and Peri (2014) to create a simple "complexity index" that summarizes the importance of these skills in defining what a complex job entails. The complexity index is:

$$
C=\left(\frac{\text { social }+ \text { analytical }}{\text { strength }}\right)
$$

where each of the separate skill indexes has been suitably transformed to account for negative values. $^{13}$

\footnotetext{
${ }^{12}$ Alternatively, introducing interactions between the indexes could reveal important synergies between different types of skills. However, interpretation of these interactions would be difficult and offer little intuition.

${ }^{13}$ We use the common transformation $I=I+1-\min (Y)$ where $\mathrm{Y}$ is the original variable, to take into account the negative values of the index.
} 
Results for the complexity index are in line with those described above. Immigrants with the same language (any/major metric) are penalized, with respect to native born workers in jobs that require the same-skill (around 7\% less wages). Note that the penalty is very similar for those speaking languages that are closely related linguistically (level 4). The penalty is lower under the stricter metric of most used language.

Overall these results confirm that differences in returns between immigrants and the native born are mostly driven by penalties associated with the returns to social skills. Even those coming from English speaking countries suffer such penalty. These immigrants do not see lower returns to their other skills, but the skill combination of their jobs is such that it results in lower wages when combined in the composite index. The difference in the penalty associated to those from English speaking countries under the two metrics employed suggests that half of that penalty is due to linguistic related differences (hence, they exist even for those for whom the most used language is English). The remaining difference could be associated with real exposure to English among immigrants or to some other characteristic correlated with their place of birth not picked up by our control variables.

\section{Section 3.3. Does LP affect the rate of wage assimilation?}

As mentioned, our estimates so far capture the average effect of LP on immigrants with different lengths of stay in the country. A relevant question is whether or not LP is related to the rate of wage assimilation over time in Canada. It is plausible that closer linguistic proximity allows for faster learning and that this translates into a more rapid progression and labour market success. Conversely, the initial disadvantage of linguistic distance could close over time as people become proficient in the local language and that should imply catch-up by those starting further away. To unveil what pattern better fits the data, we extend the basic model to consider a fully flexible specification of the arrival-cohort movements through the four census years in the sample. We follow immigrants with (potentially) different levels of linguistic proficiency by their entry cohort over time á la Borjas (1985) to examine the role of language fluency in labor market outcomes with time in Canada.

$$
\begin{gathered}
\log \left(w_{i}\right)=X_{i} \beta_{1}+\beta_{2} \sum_{s=1} \text { skill }_{S}+\beta_{3} \sum_{l=0}^{5} L_{l}+\beta_{4} \sum_{l} \sum_{t} \quad \sum_{j=1}^{4} \text { Coh }_{j} * \text { year }_{t} * L_{l}+ \\
\beta_{5} \sum_{t=90}^{00} \text { year }_{t}+\epsilon_{t}
\end{gathered}
$$


where $C o h_{j}$ are indicators designating $j$ five-year immigrant arrival cohorts, that are interacted with the indicators for survey year $\left(\right.$ year $\left._{t}\right)$ and the six linguistic proximity indicators $\left(L_{i}\right)$. Cohorts are defined over five years (i.e. the 86-90 cohort includes individuals arriving between 1986 and 1990). Equation (2) includes 60 relevant interactions (10 cohort*time indicators times 6 indicators of linguistic proximity). $\beta_{4}$ is the vector of coefficients that tracks the assimilation of immigrant cohorts by linguistic distance. ${ }^{14}$ Note that this is a more flexible approach than that achieved if using $y s m$, since the rates of change are not constrained to be the same for a given cohort.

Figure 3 shows estimated weekly wages by time in Canada for each arrival cohort of immigrant men relative to similar natives, separately for the any official/major and the most used metrics. For simplicity, we only include results for immigrant men whose languages share no branches with English (and French when any official/major metric is employed) (denoted by $\mathrm{LP}=$ None and represented with the dotted line) and for those with the same language (denoted by $\mathrm{LP}=$ Same and represented with the continuous line). Weekly wages for other levels of LP lie in between those lines.

The weekly wages of those with no connection to the host country language are either between 35 and 25 percent lower or 40 to 30 percent lower at arrival than those of the native born when employing any/major and most used metrics respectively. All arrival cohorts experience some wage improvement, around a 10\% increase, during the first five-ten years in the country, but very little after that. Their wages remain between 20 and 25 percent - depending on the metric used - below those of the Canadian born after 15 years in Canada.

For immigrants with the closest linguistic proximity, even though they always perform better than immigrants with no linguistic connection, the evolution of relative wages depends on the particular metric employed. The most used language metric generates flat estimates of wages that are indistinguishable, for the most part, from those of the native born. As a result there is little need of assimilation after 10 years in Canada (none for the later cohort) In contrast, when any official/major is employed, estimated wages increase with time in the country but start 25 to 15 percent lower than those of the native born. The fact that wage assimilation takes longer when we broaden our measure suggests that exposure to English in the country of origin is imperfect among those who migrated and learning takes place while in Canada. Alternatively, it can signal other

\footnotetext{
${ }^{14}$ The model also includes a single indicator for all cohorts arriving before 1986, so that coefficients are relative to the native born.
} 
types of barriers, such as lack of networks, which migrants overcome with time in the country. Either explanation is supported by the fact that wage assimilation still takes place at a faster rate for these immigrants - with only potentially imperfect exposure to English - than for those with no English among official/major languages in their country (Figure 3(a)). Unfortunately, we cannot rule out other influences - such as ethnicity - in our estimates even though we control for place of birth. But to the extent that the any official/major metric picks up imperfect exposure to English, these results suggest that language ability plays a role in the rate of wage assimilation.

\section{Is linguistic proximity associated with better jobs for immigrants?}

In this part of the analysis, we use skill indices as dependent variables in our basic regression to analyze the relation between LP and the characteristics of the jobs immigrants hold. Our preliminary assessment looks at the correlation between LP and skills in a regression similar in spirit to (1). After controlling for different measures of human capital, immigrant men with more distant languages typically hold jobs requiring more strength skills and less analytical or social skills than the native born (Table 3A in the Appendix). Consistent with the findings for wages, these differences are more muted when employing the any official/major instead of the most-used metric.

To study whether the Canadian immigration policy that focuses on high-educated immigrants is successful in selecting immigrants that move into "good" jobs, we assess whether the previous results vary by the level of educational attainment. We include an interaction between an indicator for university-education univ and linguistic proximity in the model

$$
S_{i}=X_{i} \beta_{1}+\beta_{2} \sum_{l=0}^{5} L_{l}+\beta_{3} \sum_{l} \text { univ } * L_{l}+\beta_{4} \sum_{t=90}^{00} \text { year }_{t}+\epsilon_{t}
$$

where $S_{\mathrm{i}}$ denotes the level of a particular skill required by the job held by worker $i$.

Results from this regression are presented in Table 6. In panel A we show estimates of skills required in jobs held by immigrants with varying degrees of LP relative to non-university educated native born workers. For instance, in the last column, university-educated immigrants, from English-speaking countries, work in jobs requiring 1.28 SD more analytical skills than nonuniversity educated native born workers. In panel B we show the differences with respect to university educated native born. University educated immigrants from English speaking countries work in jobs that require 0.14 SD less analytical skills than university-educated native born (1.28$1.42=-0.14$ ), similar social skills and 0.10 SD higher strength skills. A similar finding for all immigrant women to Canada with respect to natives is reported in Adserà and Ferrer (2014). 
Closer linguistic proximity is associated with better jobs among non-university educated immigrants to a similar extent than it is among the educated ones. In general, university-educated immigrants whose languages share at least two levels or more with English work in jobs requiring slightly lower social skills - some times more analytical skills - and more strength skills than university-educated natives. Even though the pattern is similar across metrics, the any official/major metric implies less variation across levels of linguistic proximity. ${ }^{15}$ Interestingly, when using any/major metric, immigrants with no LP (such as the large share of Chinese) access jobs with high levels of social and analytical skills, even relative to those who speak the same language (a group that includes here Philippine and Indian immigrants).

If LP facilitates the acquisition of the local language, the job standing of immigrants with less distant languages, as measured by the use of "high-status" skills (more social and analytical skills and less physical strength), should be higher, or improve faster than those of other migrants. To examine this, we estimate the relationship between the skills required by jobs and an interaction of both LP and arrival-cohort interactions over time.

$$
S_{i}=X_{i} \beta_{1}+\beta_{2} \sum_{l=0}^{5} L_{l}+\beta_{3} \sum_{l} \sum_{t} \quad \sum_{j=1}^{4} \operatorname{Coh}_{j} * \text { year }_{t} * L_{l}+\beta_{4} \sum_{t=90}^{00} \text { year }_{t}+\epsilon_{t}
$$

where $S_{\mathrm{i}}$ denotes the level of a particular skill required by the job held by worker $i$ and all other variables are defined as before.

Figure 4 displays how the skill requirements of the jobs that immigrants hold (relative to similar natives) change with years in Canada for different levels of LP to English (most-used metric). Overall, there is little evidence that skills improve (or change much) with years since arrival. Immigrants, for whom English is the most used language in their country of origin (continuous line), work in jobs that are very similar to those of the native born in terms of strength and social skills and slightly better in terms of analytical skills. Further, their relative position remains stable or converges toward natives over time. Immigrants with no linguistic proximity to English work in jobs requiring around 0.2 SD of strength above those required to the average worker, between 0.3 to 0.4 SD lower social skills, and around 0.25 lower analytical skills. The

\footnotetext{
15 The difference between those with a Canadian language and those with no linguistic proximity, among educated immigrants, social skills $0.37=1.54-1.17$; analytical skills $-0.01=1.28-1.29$. Among the non-university educated immigrants, social skills $0.30=0.11-(-0.19)$; analytical skills $0.27=0.17-(-0.10)$
} 
levels of strength required in their jobs rise slightly with time in Canada and for successive cohorts, whereas social and analytical skills remain relatively stagnant (or even decline) over time for all cohorts. ${ }^{16}$

The above result is puzzling considering the relatively high level of education of Canadian immigrants. One would expect higher levels of education to enable immigrants to gain job-status even if they are initially under-placed. We present in Figure 5 estimates of skill progression only for university educated immigrants with respect to similar natives. These show a modest reduction in strength (increase in social) skills requirements with time in the country, even for those without any connexion to English. However, there is a substantial increase in analytical job-required skills for these immigrants. ${ }^{17}$ Hence, linguistic proximity seems to affect the type of jobs immigrant hold over time. The fact that it does not appear to influence the change in the skill content of jobs held by immigrants over time in Figure 4, only masks the differential effect that it has for university versus non-university educated immigrants

Migration studies are typically compelled to trade off the advantages of large samples that allow detailed analysis of immigrant characteristics with other essential information such as longitudinal records usually available in much smaller samples. With our data we cannot address whether the correlation between language fluency and performance over time is due to unobserved innate characteristics of immigrants rants. As result, we can only interpret our results - particularly those of changes over time - as associations between LP and the aggregated performance of immigrants. Nevertheless, our results agree with those of previous longitudinal studies that show language proficiency complements occupational skills (Berman et al. 2008) and that affects the set of jobs accessible to immigrants at arrival (Imai et al. 2014).

\section{Are Immigrants better off in Quebec than elsewhere in Canada?}

One of the most interesting aspects of studying the impact of language on the assimilation of immigrants in Canada relates to this country's bilingualism. The official languages of Canada are English and French, which "have equality of status and equal rights and privileges as to their use in all institutions of the Parliament and Government of Canada," (Subsection 16(1) of the Constitution

\footnotetext{
${ }^{16}$ Results using any official/major language metric are qualitatively similar to those in figure 4, and are available upon request.

${ }^{17}$ Similar results are reported for immigrant women in Adsera and Ferrer (2014).
} 
Act, 1982). In this spirit, we employed the linguistic proximity to either French or English for the “Any official/Major" metric in our analysis so far.

In practice, however, Canadian bilingualism is clearly distributed geographically, with most of the French speakers (only) concentrating in Quebec (86\%). ${ }^{18}$ This is partly due to the fact that Quebec has a completely separated immigrant application process. The Federal government controls the number of admission to Canada, but Quebec retains ownership over the right to select immigrants to settle within the province. Immigrants to Quebec must first obtain a Cértificat du Sélection du Québec (Quebec Selection Certificate, commonly known as a CSQ), which are assessed at the provincial level by a different selection mechanism than that used by the Federal government (see table 5 in the appendix). Similarly, Quebec and the rest of Canada (ROC) receive a different mix of immigrants across entry gates. Over the period 1980-2001, Quebec had a greater percentage of its entrants in the economic class (43\% vs. 35\%) than RoC. ${ }^{19}$ However, the fraction of economic immigrants across provinces has equalized between 2001 and 2006 (Quebec received $60 \%$ of immigrants in the economic category and RoC received around 59\%).

This setting of immigration offers the opportunity to check whether results follow the same pattern in Quebec as elsewhere and to ponder whether the fact that English is heavily studied as a second language in many countries and is present in most media may somewhat dampen the relevance of the linguistic distance to English compared to other languages (Adserà an Pytlikova 2015).

To conduct this exercise, we compare the effect of linguistic proximity to either French (only) or English (only) on the labour market outcomes of immigrants residing in Quebec versus those in the Rest of Canada (RoC). Table 2 shows the major immigrant source countries associated to each level of linguistic proximity to French (only) or English (only) indexes. Overall, we expect that French (English) speaking immigrants in Quebec (RoC) experience minimal wage penalty, but a larger one if residing outside Quebec (outside RoC). Similarly, the performance of immigrants with only limited (first level) proximity to English but close proximity to French (such as those from South and Central American countries, Spain, Italy, or Portugal) should be better when residing in Quebec

\footnotetext{
${ }^{18}$ Statistics Canada Catalogue no. 97-555-XWE2006002. Note that a large fraction of bilingual speakers (French and English) - 44\% - and of immigrants who are bilingual in French and other non-official language - 72\% - also reside in Quebec.

${ }^{19}$ Citizenship and Immigration Canada 2010 and DeVoretz and Pivnenko (2008))
} 
rather than in RoC. Conversely, those with limited (first level) linguistic affinity to French but close to English (Germany, the Netherlands) should experience larger penalties when living in Quebec. Panel A in Table 7 shows the coefficients from a basic model that includes an interaction of the immigrant and Quebec residence indicators. The models in Panel B include a full set of linguistic proximity indicators to either English (first column) or French (second column). For sake of brevity only results using the "Most used" metric are presented.

In Panel A, wages of Canadian-born residents in Quebec are 12.4\% lower than those of Canadian born residing in Ontario, and wages of immigrants outside of Quebec are $18.2 \%$ lower than those of their co-resident natives. Immigrants in Quebec receive wages around 5.3\% lower than native-born residents in Quebec and overall 17.7\% (12.4+5.3) below non-Quebecois immigrants. Panel B reports immigrant weekly wages by LP to either French (column I) or English (Column II) relative to the natives in RoC. By this measure, immigrants perform better outside Quebec than in Quebec - regardless their level of LP to French.

To better grasp the effect of province of residence, Panel A in Table 8 computes the wage difference between immigrants in Quebec with a given linguistic proximity to French and those residing elsewhere in Canada. Weekly wages for those who share no common branch with French (i.e., China) are 5\% lower in Quebec. That difference grows to 8\% for immigrants with a first level of linguistic proximity (mainly Indians but also those from Germany, the US and the UK). Despite the relative closeness of languages, wages for immigrants with three branches in common with French (Romania) are 15\% lower in Quebec than in RoC. Immigrants sharing four branches in common with French (Italy and Portugal) still experience large wage penalties - a 10\% reduction in wages when settling in Quebec instead of RoC. Finally, there are not significant penalties for French speaking immigrants who earn similar wages anywhere in Canada.

Column 2 in Table 8, reports the difference between immigrants in Quebec with a given distance to English versus those in RoC. As with distance to French, immigrants sharing no common branch with English (such as Chinese) experience an additional 5\% reduction in wages if settling in Quebec. However this difference is small (only 1.6\%) for immigrants who share one branch with English (a group which now includes, besides India and Greece, all the Romance languages). Immigrants from places where the most used language shares two branches in common with English (Nordic countries) make 10\% more in Quebec than in RoC. We attribute these non- 
linear effects to the sharp differences in exposure to second languages in Europe ${ }^{20}$ Finally, among immigrants with close proximity to English (sharing 3 branches or more) there is no significant difference in earnings across Canada.

To study whether the characteristics of migrants' jobs vary by location, Table 9 shows the difference in job-required skills of immigrants compared to natives in their province by distance to either French or English. As expected, jobs held by immigrants with no LP to English tend to require more strength skills and substantially lower analytical and social skills than those held by the native born (as in Figure 3). Surprisingly, jobs of immigrants with no affinity to French require lower levels of all skills than the native-born in their province regardless of where they settle. Immigrants with no French who settle in Quebec work higher status jobs in their province of residence than immigrants with no English that settle in RoC, Their jobs require less strength (-0.083 SD of strength) and only slightly lower analytical and social skills (-0.029 SD and -0.056 SD respectively) than jobs of native-born Quebecoise. However, immigrants with no English settling in RoC work in jobs requiring more strength (0.071 SD of strength) and much lower analytical and social skills (-0.178 SD and -0.277 SD respectively) than jobs of native-born in RoC. Similarly, differences in skills with respect to the native born are smaller for immigrants who share only one linguistic branch with French (for example, 0.102 SD lower analytical skills than natives in Quebec) than one branch with English (0.275 SD lower analytical skills than natives in RoC). However, those linguistically closer to French (sharing 4 branches or more) perform relatively poorly in terms of job skills if residing in Quebec (requiring 0.081 SD higher strength and 0.208 and 0.272 SD lower analytical and social skills than natives), compared to immigrants relatively close to English (3 branches or higher) residing outside Quebec (whose jobs require 0.002 SD higher strength and 0.021 (0.104) SD lower analytical (social) skills than natives).

Panel B of Table 8, shows the difference in required job skills between immigrants residing in Quebec and those in RoC. In general, most immigrants residing in Quebec have jobs with lower levels of strength (negative) and higher levels of social and analytical skills (positive) than immigrants of similar LP proximity (to either French or English) residing outside Quebec. The only exception to this pattern happens among those with $3^{\text {rd }}$ level LP to English - Germans and Dutch. These immigrants generally work in jobs requiring less analytical or social skills, and similar

\footnotetext{
${ }^{20}$ For instance, until recently, the prevalence of English as a second language was very large in Northern Europe, but much lower in Southern Europe. More than $80 \%$ of the population in Scandinavian countries speaks fluent English (http://www.vox.com/2014/11/17/7082317/language-maps-charts; item 11). 
strength skills, when working in Quebec compared to RoC. One explanation for this finding could lie in structural differences between the Quebecois economy and the RoC. However, this is not supported by results from Table 8 showing that natives in Quebec work in positions with more strength and less analytical and social requirements than in the rest of Canada. Alternatively, it might follow from the urban nature of Canadian migration: most immigrants to Quebec settle in Montreal, where English is commonly used in the service sector, and immigrants with close LP to English are able to perform quite well.

\section{Conclusion}

We combine the large samples of the restricted version of the Canadian Census (1991-2006) with both a new measure of linguistic proximity of the immigrant's mother tongue to that of the destination country and with information on the occupational skills embodied in the jobs immigrants hold. This allows us to assess the role that language plays in the labour market performance of immigrants and to better study their progression in a variety of labour market dimensions relative to the native born.

Our results show that linguistic proximity affects the returns to human capital and skills of immigrant men. Though it crucially matters in determining the level of such returns, it does not seem to influence how fast wage-parity is attained between immigrants and the native born. Linguistic proximity also influences the skills required in the jobs immigrants hold; however, we do not find evidence that it affects the speed of assimilation into better jobs. A larger linguistic distance imposes larger wage penalties to the university-educated than to those with lower educational attainment, and it significantly affects the status of the jobs they hold. To the extent that immigrants might be selected on the basis of their language ability, these results may underestimate the importance of linguistic proximity on the outcomes of immigrants.

The cross-sectional nature of our data does not allow us to properly assess the mechanisms through which language correlates with performance. Human capital theory suggests that LP will be correlated with higher wages, as well as faster rates of wage progression and job-status advancement over time. Moreover, LP is likely to be complementary to education. Our results generally agree with these predictions, but with our cross-sectional data we are unable to assess the causal pathways behind these findings. Our results are close to those found by previous longitudinal studies that employed limited samples. Thus, we believe that they should be robust to addressing biases due to variation in individual ability. 
Another surprising finding concerns the lack of wage convergence and indeed the small rate of job status mobility experienced over time by individuals with no linguistic proximity to Canadian languages. According to the human capital model, these results could arise from a lack of improvement in language skills - for instance if ethnic enclaves exist that limit economic opportunities. However, it is possible that there are systematic barriers that limit integration and that can be (or not) related to language proficiency. This could be the case if, as noted in related research, immigrants arriving as adults may never reach the level of proficiency required to access certain types of high level jobs. 


\section{References}

Adserà and Ferrer, (2014) "The Myth of Immigrant Women as Secondary Workers: Evidence from Canada” AER papers and proceedings, 104(3), pp.360-364

Adserà, A. and Pytliková, M. (2015) “The Role of Languages in shaping International Migration”, Economic Journal Vol. 125, Issue 586, pp. F49-F81.

Antecol H, Kuhn P and Trejo S (2006) Assimilation via Prices or Quantities? Sources of Immigrant Earnings Growth in Australia, Canada and the United States. Journal of Human Resources 41: 821-840

Autor, D. (2013) “The "Task Approach" to Labor Markets: An Overview” NBER Working Papers 18711.

Autor, D. and D. Dorn (2013) The Growth of Low-Skill Service Jobs and the Polarization of the U.S. Labor Market, American Economic Review, 103(5), 1533-1597, 2013.

Autor, D. and M. J. Handel, 2013. "Putting Tasks to the Test: Human Capital, Job Tasks, and Wages," Journal of Labor Economics, University of Chicago Press, vol. 31(S1), pages S59 S96.

Aydemir, A. and Skuterud, M. (2005) "Explaining the Deteriorating Entry Earnings of Canadian Immigrant Cohorts: 1966-2000”, Canadian Journal of Economics, Vol. 38(2), pp. 641-72.

Begin, K., C. Goyette and W. C. Riddell (2010). “Revising Canada’s Immigrant Selection System: An Assessment of Recent Changes” Background paper prepared for Citizenship and Immigration Canada.

Berman, E., K. Lang, E. Siniver (2003) "Language-skill complementarity: returns to immigrant language acquisition”, Labour Economics 10 (1): 265-90

Bleakley H. and A. Chin (2004) "Language Skills and Earnings: Evidence from Childhood Immigrants.” Review of Economics and Statistics 84 (2): 481-496.

Borjas,G. (2013) "The Slowdown in the Economic Assimilation of Immigrants: Aging and Cohort Effects Revisited Again”, NBER Working Papers 19116,

Borjas, G. (1985) "Assimilation and Changes in Cohort Quality Revisited: What Happened to Immigrant Earnings in the 1980's?" Journal of Labor Economics 3, pp. 463-89.

Bratsberg, B. and O. Raaum (2004) Identifying Earnings Assimilation of Immigrants under Changing Macroeconomic Conditions. Scandinavian Journal of Economics 106: 1-22

Chiswick, B. R. 1978 “The Effect of Americanization on the Earnings of Foreign-Born Men”. Journal of Political Economy 86(5): 897-922.

1986, “Ìs the New Immigration Less Skilled Than the Old?” Journal of Labor Economics, 4(2):168-192

Chiswick, B. and P. Miller (2002) "Immigrant Earnings: Language Skills, Linguistic Concentrations and the Business Cycle.” Journal of Population Economics 15(1): 31-57.

Chiswick, B., and P.W. Miller. (2003) "The complementarity of language and other human capital: immigrant earnings in Canada” Economics of Education Review Vol. 22. No.5. p. 469-80.

Chiswick, B. and P. Miller (2007) "Computer Usage, Destination Language Proficiency and the Earnings of Natives and Immigrants.” Review of the Economics of the Household 5 (2): 129-157. 
Chiswick, B. and P. Miller (2010) “Occupational Language Requirements and the Value of English in the US Labor Market.” Journal of Population Economics 23(1): 353-372.

DeVoretz, D. and S. Pivnenko (2008) “The Immigration Triangle: Quebec, Canada and the rest of the World” Journal of International Immigration and Integration, vol.9(1) pp: 363-381

Dustmann, C. (1994) "Speaking Fluency, Writing Fluency and Earnings of Migrants.” Journal of Population Economics 7: 133-56.

Dustmann, C. and A. van Soest (2001) "Language Fluency and Earnings: Estimation with Misclassified Language Indicators.” The Review of Economics and Statistics 83 (4): 663-674.

(2002) "Language and the Earnings of Immigrants.” Industrial and Labor Relations Review 55 (3): 473-492.

Dustmann C and Fabbri F (2003) Language Proficiency and Labour Market Performance of Immigrants in the UK. Economic Journal 113: 695-717

Faged and Peri, G. (2014) “Immigrants' effect on native workers: New analysis on Longitudinal Data” CReAM CPD 07/15

Ferrer, A., G. Picott and C. Riddell (2014), “New Directions in Immigration Policy: Canada’s Evolving Approach to Immigration Selection”, forthcoming International Migration Review, CLSRN working paper \#107

Ferrer, A.M., and C. Riddell (2008), “Education, credentials and immigrant earnings”, Canadian Journal of Economics, vol. 4(1), pp. 186-216

Ferrer, A.M., D. Green, C. Riddell (2006), “The Effect of Literacy on Immigrant Earnings”, The Journal of Human Resources vol. 41(2) p. 380-410

Friedberg R (2000) You Can't Take it With You: Immigrant Assimilation and the Portability of Human Capital. Journal of Labor Economics 18: 221-51

Houle, F. (2014) “Implementing Québec Intercultural Policy Through the Selection of Immigrants" in Immigration regulation in federal states: challenges and responses in comparative perspective, International Perspectives in Immigration, vol (9) Baglay, Sasha ; Nakache, Delphine eds. Springer, New York

Imai, S., D. Stacey and C. Warman (2011) "From Engineer to Taxi Driver? Occupational Skills and the Economic Outcomes of Immigrants," Working Papers 1275, Queen's University,

Ingram, B. and G. Neumann (2006) “The returns to skill.” Labour Economics 13 (1):35-59

Kossoudji, S. (1988). "The Impact of English Language Ability on the Labor Market Opportunities of Asian and Hispanic Immigrant Men.” Journal of Labor Economics 6 (3): 205-228.

Lewis, P. (ed.) (2009) Ethnologue: Languages of the World, Sixteenth edition. Dallas, Tex.: SIL International. Online version: http://www.ethnologue.com/.

Qing Li \& Arthur Sweetman, 2013. "The Quality of Immigrant Source Country Educational Outcomes: Do they Matter in the Receiving Country?,", CReAM Discussion Paper Series 1332.

OECD, 2014. "Who should be admitted as a labour migrant?”, Migration Policy Debates 4, http://www.oecd.org/els/mig/OECD\%20Migration\%20Policy\%20Debates\%20Numero\%202.pdf

Canada Facts and Figures 2010, Citizenship and Immigration Canada 
Schaafsma, J. and A Sweetman (2001). “Immigrant earnings: age at immigration matters”, Canadian journal of Economics, vol. 34(4), pp. 1066-1099

Sweetman, Arthur \& Warman, Casey, 2009. "Temporary Foreign Workers and Former International Students as a Source of Permanent Immigration," CLSRN WP \#2009-34.

Warman, C. and C. Worswick (2015) "Technological Change, Occupational Tasks and Declining Immigrant Outcomes: Implications for Earnings and Income Inequality in Canada," NBER Working Papers 21307, 
Table 1. Sample Summary Statistics. Census 1991-2006

\begin{tabular}{|c|c|c|c|c|}
\hline & & Canadian born & Im & \\
\hline Age & & 39 & & \\
\hline Marital Status & & & & \\
\hline HS or & & 0.52 & & \\
\hline Post-s & condary (other) & 0.33 & & \\
\hline Bache & & 0.12 & & \\
\hline Gradu & & 0.04 & & \\
\hline Labour Force Particip & tion & 0.86 & & \\
\hline & Social & -0.09 & & \\
\hline Job skill index ${ }^{1}$ & Strength & 0.29 & & \\
\hline & Quantitative & 0.04 & & \\
\hline & & & Any/Major & Most used \\
\hline & None & & 0.18 & 0.44 \\
\hline & 1st Level & & 0.16 & 0.37 \\
\hline Linguistic proximity & 2nd Level & & 0.01 & 0.00 \\
\hline to English 2 & 3rd Level & & 0.05 & 0.04 \\
\hline & 4th Level & & 0.18 & -- \\
\hline & Same Language & 1.00 & 0.43 & 0.14 \\
\hline Levenshtein ${ }^{3}$ & & & 50.16 & 80.40 \\
\hline \# Observations & & $1,218,305$ & & \\
\hline
\end{tabular}

(1) The skill index is calibrated and normalized to the Canadian native born population (men and women) in 2001, so that 0 corresponds to the average Canadian worker in 2001.

(2) Linguistic Proximity for the "Any/Major" metric corresponds to the highest common branch in the linguistic tree between any official and the two most widely spoken languages at origin and English or French (official languages in Canada). For the "Major" metric it corresponds to of the highest common branch in the linguistic tree between the most used language at origin and English (most commonly used language in Canada)

(3) Levenshtein measures linguistic distance from 0 (same language) to around 106. 
Table 2. Main immigrant source countries in Canada by Linguistic Proximity (LP)

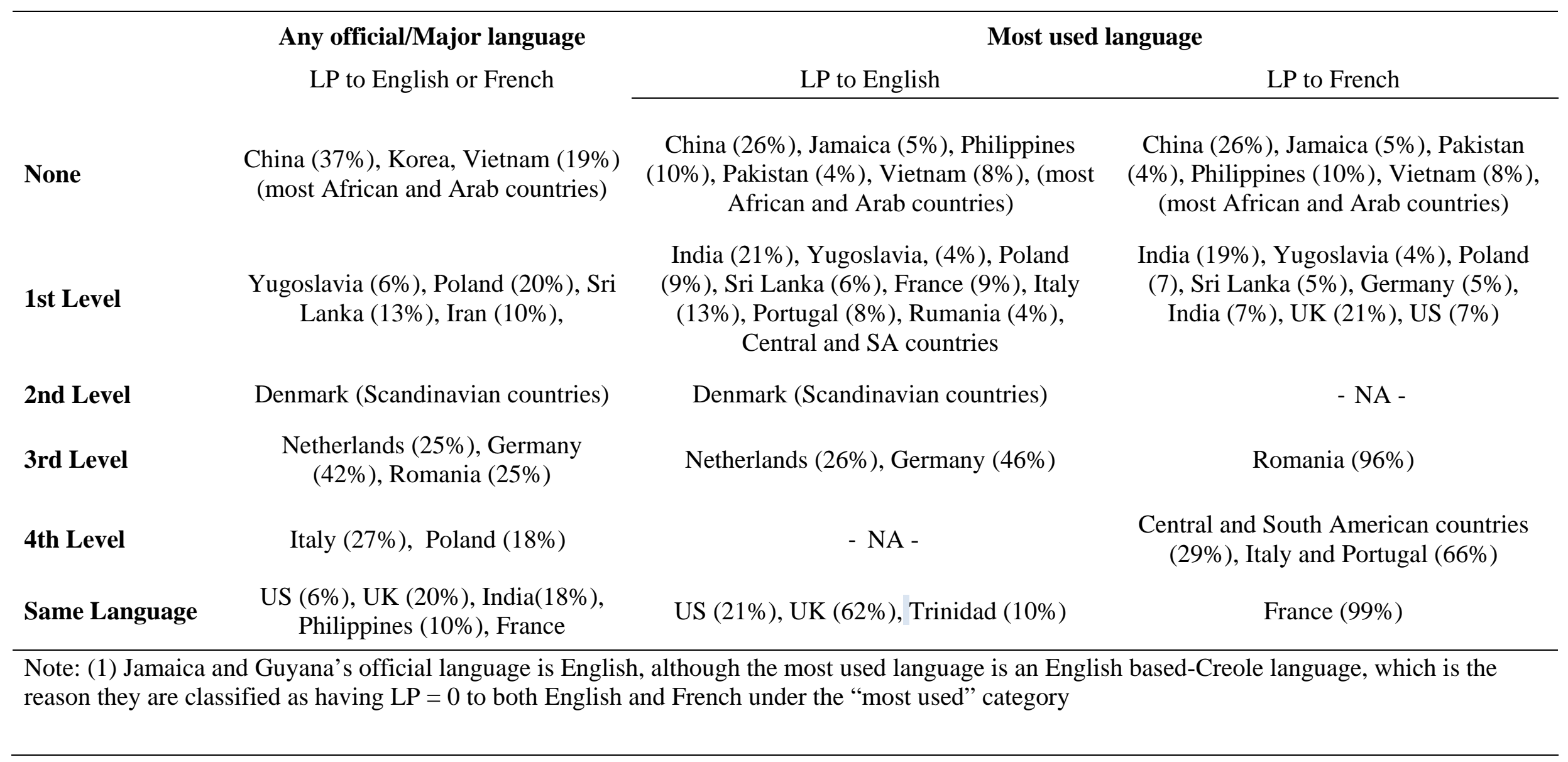




\section{Any official/ Major language}

(1)
(2)
(3)

\section{Most used language}

(4)

(5)

(6)

\section{Skill index of Jobs}

$\begin{array}{lcccccc}\text { Social } & 0.01^{* * *} & 0.01^{* * *} & 0.01^{* *} & 0.01 * * & 0.01^{* * *} & 0.004^{* *} \\ \text { Strength } & -0.08^{* * *} & -0.08^{* * *} & -0.08^{* * *} & -0.08^{* * *} & -0.08^{* * *} & -0.08^{* * *} \\ \text { Analytical } & 0.16^{* * *} & 0.16^{* * *} & 0.17^{* * *} & 0.16^{* * *} & 0.16^{* * *} & 0.17^{* * *}\end{array}$

\section{LP indicators}

None

1st Level

2nd Level

3rd Level

4th Level

Same Language

Immigrant

Levenshtein Index

POB control ${ }^{1}$

\# Observations

$\begin{array}{cc}-0.32^{* * *} & -0.16^{* * *} \\ -0.28^{* * *} & -0.29 * * * \\ -0.09^{* * *} & -0.01 \\ -0.21^{* * *} & -0.27 * * * \\ -0.17^{* * *} & -0.05^{* * *} \\ -0.18^{* * *} & -0.06 * * *\end{array}$

$-0.34 * * *$

$-0.24 * * *$

$-0.07 * * *$

$-0.21 * * *$

$-0.06 * * *$

$-0.16^{* * *}$

$-0.001^{* * *}$

No

Yes

No

No

$1,353,560$

$1,353,560$

$-0.19 * * *$

-0.20 ***

$-0.03$

$-0.18^{* * *}$

$-0.03^{* * *}$

All regressions include, in addition, controls for marital status, experience, experience squared, education, visual and motor job-skills, location, GDP per capita at country of origin and survey year. Individuals are 18 to 60 years old. Immigrants are adults at arrival.

Any official/Major language indicates that linguistic proximity is measured between either any official language or the two most widely-spoken languages at origin and the two official languages at destination (English or French). Most used language indicates that distance is measured between the most commonly used language at origin and the most commonly used language at destination (English). The Levenshtein index increases with linguistic distance.

$(* * *, * *)$ indicates the coefficient is significant at $1 \%$ or $5 \%$ respectively

${ }^{1}$ The omitted POB (place of birth) group is US/Europe 
Table 4. Effect of Linguistic Proximity and University education on immigrant weekly wages

\begin{tabular}{|c|c|c|c|c|c|c|c|}
\hline & $\begin{array}{c}\text { Native } \\
\text { Born }\end{array}$ & Same Lg & $4^{\text {th }}$ level & $3^{\text {rd }}$ level & $2^{\text {nd }}$ level & $1^{\text {st }}$ level & None \\
\hline \multicolumn{8}{|c|}{ Panel A. LP (Any official/Major language) and Education } \\
\hline Non university & Ref & $-0.03^{\star \star \star}$ & $-0.06 * \star *$ & $-0.21 * \star \star$ & 0.01 & $-0.28^{\star \star \star}$ & $-0.10^{* * *}$ \\
\hline University & $0.65^{\star \star \star}$ & $0.54^{\star \star \star}$ & $0.61 * \star \star$ & $0.33^{\star \star \star}$ & $0.68 * \star \star$ & $0.25^{\star \star \star}$ & $0.45^{\star \star \star}$ \\
\hline \multicolumn{8}{|c|}{ Panel B. LP (Most used language) and Education } \\
\hline Non university & Ref. & 0.00 & & $-0.18 * \star \star$ & -0.02 & $-0.19 * \star \star$ & $-0.18^{\star \star \star}$ \\
\hline University & $0.65^{\star \star \star}$ & $0.64^{\star \star *}$ & & $0.53^{* * *}$ & $0.71^{\star \star *}$ & $0.31^{\star \star *}$ & $0.40^{\star \star \star}$ \\
\hline
\end{tabular}

The first column shows the effect of university education on the native born. The other columns show the effect of linguistic proximity for immigrants with and without university education relative to non-university educated native born. Calculations based on the coefficients from estimating equation 3.

Panel A shows the effect when measuring linguistic proximity by proximity between any official or major languages at origin and English/French. Panel B shows the effect when measuring linguistic proximity by proximity between the most commonly used language at origin and English.

Both regressions include controls for marital status, experience, experience squared, education, motor and visual job skills and their interactions with university education, location, GDP per capita at country of origin, place of origin (US/Europe is the omitted group) and survey year. Individuals are 18 to 60 years old. Immigrants are adults at arrival. Regressions have 1,353,560 observations

$\left({ }^{* * *}\right)$ indicates that coefficient (or combined coefficients) is significant at $1 \%$ 
Table 6. Effect of linguistic proximity and university education on required job skills (relative to non-university educated natives)

(Any Official/Major Language)

(Most used Language)

Skills in jobs

Strength Social Analytica

Strength

Social

Analytical

PANEL A. Estimates relative to non-educated native born

Non-University (NB)
Imm - Same Language
Imm - $4^{\text {th }}$ Level
Imm - $3^{\text {rd }}$ Level
Imm - $2^{\text {nd }}$ Level
Imm - $1^{\text {st }}$ Level
Imm - None

$\begin{array}{cc}\text { Ref } & \text { Ref } \\ -0.01^{*} & -0.02 * * * \\ 0.07 * * * & -0.14 * * * \\ -0.01 * & -0.06 * * * \\ 0.06 * * & -0.06 * * * \\ 0.09 * * * & -0.20 * * * \\ -0.03 * * * & 0.03 * * *\end{array}$

$\begin{array}{cc}\text { Ref } & \text { Ref. } \\ 0.02 * * * & -0.12^{* * *} \\ -0.07 * * * & -- \\ 0.02 * * & -0.04 * * * \\ 0.06 * * & 0.00 \\ -0.16^{* * *} & 0.20 * * * \\ 0.08^{* * *} & 0.09 * * *\end{array}$

Ref

Ref

University (NB)

$-1.35^{* * *}$

$1.57 * * *$

$1.44 * * *$

$-1.33^{* * *}$

$0.11 * * *$

$0.17 * * *$

Imm - Same Language

$-1.18 * * *$

$1.39 * * *$

$1.34 * * *$

$-1.24 * * *$

$-0.04 * * *$

$0.05 * * *$

Imm - $4^{\text {th }}$ Level

$-1.35 * * *$

$1.51 * * *$

$1.58 * * *$

$1.37 * * *$

$1.48 * * *$

0.01

$0.10 * * *$

Imm - $3^{\text {rd }}$ Level

$-1.30 * * *$

$1.44 * * *$

$1.45^{* * *}$

$-1.25 * * *$

$-0.31 * * *$

$-0.22 * * *$

Imm - $2^{\text {nd }}$ Level

$-1.33 * * *$

$1.22 * * *$

$1.31^{* * *}$

$-1.40 * * *$

$-0.19 * * *$

$-0.10 * * *$

Imm - $1^{\text {st }}$ Level

$-1.15^{* * *}$

$1.45^{* * *}$

$1.50 * * *$

$-1.08 * * *$

$1.55^{* * *}$

$1.42 * * *$

$-1.23 * * *$

$-1.06 * * *$

$1.54^{* * *}$

$1.28^{* * *}$

--

$1.37^{--}$

$1.43^{* * *}$

$1.49 * * *$

Imm - None

\begin{abstract}
(1.23
\end{abstract}
PANEL B. Skill Differences between educated immigrants and native born with varying degrees of LP

$\begin{array}{lcccccc}\text { Imm - Same Language } & 0.17^{* * *} & -0.18^{* * *} & -0.10^{* * *} & 0.10^{* * *} & -0.01 & -0.14^{* * *} \\ \text { Imm - } 4^{\text {th }} \text { Level } & 0.00 & -0.05^{* *} & 0.14^{* * *} & -- & -- & -- \\ \text { Imm - } 3^{\text {rd }} \text { Level } & 0.05^{* * *} & -0.20^{* *} & 0.04^{*} & 0.08^{* * *} & -0.11^{* * *} & -0.05^{* *} \\ \text { Imm - } 2^{\text {nd }} \text { Level } & 0.02 & -0.12^{*} & 0.02 & -0.06^{*} & -0.06^{*} & 0.07^{*} \\ \text { Imm - } 1^{\text {st }} \text { Level } & 0.20^{* * *} & -0.34^{* * *} & -0.13^{* * *} & 0.26^{* * *} & -0.41^{* * *} & -0.19^{* * *} \\ \text { Imm - None } & 0.12^{* * *} & -0.11^{* * *} & 0.06^{* * *} & 0.27 * * * & -0.37^{* * *} & -0.14^{* * *}\end{array}$

Each column in panel A shows the effect of linguistic proximity and university education on job-required levels of strength, social and analytical skills in jobs, relative to those of less-educated native born. Panel B computes the difference between educated native born and immigrants with varying degrees of LP

The first three columns measure linguistic proximity by proximity between any official and major languages at origin and English/French. The last three columns measure linguistic proximity by proximity between the most commonly used language at origin and English.

All regressions include controls for marital status, experience, experience squared, location, GDP per capita at country of origin, place of origin (US/Europe is the omitted group) and survey year. Individuals are 18 to 60 years old. Immigrants are adults at arrival. Observations are 1,558,170

$(* * *, * * *)$ indicates the coefficient is significantly different from 0 at 1,5 and $10 \%$ respectively 
Table 7. Estimates of LP on weekly wages by province of residence - Relative to native born in RoC (Most used” language)

\begin{tabular}{ll}
\hline Panel A. Benchmark & \\
\hline Immigrant & $-0.182 * * *$ \\
Quebec & $-0.124 * * *$ \\
Quebec*Immigrant & $-0.053^{* * *}$ \\
\hline
\end{tabular}

Panel B. Linguistic Proximity

(I)

Quebec

\section{Immigrants in Quebec}

$\begin{array}{ll}\text { LP French }- \text { None } & -0.320^{* * *} \\ \text { LP French }-1^{\text {st }} \text { level } & -0.251^{* * *} \\ \text { LP French }-3^{\text {rd }} \text { level } & -0.357 * * * \\ \text { LP French }-4^{\text {th }} \text { level } & -0.150^{* * *} \\ \text { LP French }- \text { French } & -0.124 * * *\end{array}$

Immigrants in RoC

LP French - None
LP French $-1^{\text {st }}$ level
LP French $-3^{\text {rd }}$ level
LP French $-4^{\text {th }}$ level
LP French - French

Observations
$-0.123^{* * *}$
$-0.271^{* * *}$

$-0.173 * * *$

$-0.204 * * *$

$-0.046 * * *$

$-0.090 * * *$
(II)

Quebec

$-0.123^{* * *}$

Immigrants in Quebec

$\begin{array}{ll}\text { LP English - None } & -0.380^{* * *} \\ \text { LP English }-1^{\text {st }} \text { level } & -0.255^{* * *} \\ \text { LP English }-2^{\text {nd }} \text { level } & -0.188^{* * *} \\ \text { LP English }-3^{\text {rd }} \text { level } & -0.234^{* * *} \\ \text { LP English }- \text { English } & -0.050^{* * *}\end{array}$

\section{Immigrants in RoC}

$\begin{array}{ll}\text { LP English - None } & -0.327 * * * \\ \text { LP English }-1^{\text {st }} \text { level } & -0.239 * * * \\ \text { LP English }-2^{\text {nd }} \text { level } & -0.084 * * * \\ \text { LP English }-3^{\text {rd }} \text { level } & -0.204 * * * \\ \text { LP English }- \text { English } & -0.056 * * *\end{array}$

LP English - English

$1,354,340$

All regressions include controls for marital status, experience, experience squared, education, job-skills, location, area of origin, GDP per capita at country of origin, and survey year. Individuals are 18 to 60 years old. Immigrants are adults at arrival.

Panel B shows estimates of the interaction between linguistic proximity and province of residence. The effect shown is relative to natives of RoC. Column (I) uses LP between the most common used language at origin and French and column (II) uses LP between the most common used language at origin and English. RoC stands for Rest of Country.

$(* * *, * *, *)$ indicates the coefficient is significantly different from 0 at 1,5 and $10 \%$ respectively 
Table 8 Differences in labour outcomes between immigrants residing in Quebec versus RoC ${ }^{*}$ )

Panel A. Differences in wages of immigrants - Quebec vs. RoC.

\begin{tabular}{|c|c|c|c|}
\hline \multirow[b]{2}{*}{ LP None } & \multirow{2}{*}{$\begin{array}{c}\begin{array}{c}\text { Weekly wages } \\
\text { (using LP to French) }\end{array} \\
-0.049 * * *\end{array}$} & \multirow{2}{*}{\multicolumn{2}{|c|}{$\begin{array}{l}\begin{array}{l}\text { Weekly wages } \\
\text { (using LP to English) } \\
-0.053^{* * *}\end{array}\end{array}$}} \\
\hline & & & \\
\hline LP $\quad 1^{\text {st }}$ level & $-0.078 * * *$ & LP $1^{\text {st }}$ level & $-0.016 * *$ \\
\hline LP $3^{\text {rd }}$ level & $-0.153 * * *$ & LP $2^{\text {nd }}$ level & $0.104^{* * *}$ \\
\hline LP $4^{\text {th }}$ level & $-0.104 * * *$ & LP $3^{\text {rd }}$ level & -0.030 \\
\hline LP French & -0.034 & LP English & 0.006 \\
\hline
\end{tabular}

Panel B. Differences in job skills of immigrants - Quebec vs. RoC.

Skills

(using LP to French)

\begin{tabular}{|c|c|c|c|}
\hline & Strength & Analytical & Social \\
\hline LP None & $-0.05 * * *$ & $0.04 * * *$ & $0.09 * * *$ \\
\hline LP $1^{\text {st }}$ level & $-0.07 * * *$ & $-0.02 * *$ & 0.00 \\
\hline LP $3^{\text {rd }}$ level & -0.03 & $-0.06 * *$ & $0.06 * * *$ \\
\hline LP $4^{\text {th }}$ level & $-0.15 * * *$ & -0.02 & $0.06 * * *$ \\
\hline LP French & $-0.11^{* * *}$ & $0.06^{* *}$ & $0.07 * * *$ \\
\hline
\end{tabular}

\section{Skills}

(using LP to English)

\begin{tabular}{|c|c|c|c|}
\hline & Strength & Analytical & Social \\
\hline LP None & $-0.05 * * *$ & $0.03 * * *$ & $0.08 * * *$ \\
\hline LP $1^{\text {st }}$ level & $-0.17 * * *$ & $0.07 * * *$ & $0.12^{* * *}$ \\
\hline LP $2^{\text {nd }}$ level & -0.11 & -0.01 & 0.10 \\
\hline LP $3^{\text {nd }}$ level & -0.01 & $-0.10 * * *$ & $-0.03^{*}$ \\
\hline LP English & $-0.04 * * *$ & 0.01 & $0.08 * * *$ \\
\hline
\end{tabular}

$(* * *, * *, *)$ indicates the coefficient is significantly different from 0 at 1,5 and $10 \%$ level respectively. Significance is calculated using an F-test of the differences in coefficients from the regressions in Table 7 (Panel A) and 8 (panel B) 
Table 9. Effect of language on job skills of male immigrant, by linguistic proximity (Quebec relative to RoC, Immigrants relative to similar natives in their province of residence)

\section{Using LP to French}

$\begin{array}{lccc} & \text { Strength } & \text { Analytical } & \text { Social } \\ \text { Quebec } & 0.013^{* * *} & -0.077^{* * *} & -0.064^{* * *} \\ \text { Immigrant in Quebec } & & & \\ \text { LP French - None } & -0.083^{* * *} & -0.029^{* * *} & -0.056^{* * *} \\ \text { LP French - } 1^{\text {st }} \text { level } & 0.012^{* * *} & -0.102^{* * *} & -0.150 * * * \\ \text { LP French }-3^{\text {rd }} \text { level } & 0.069^{* * *} & 0.033 & -0.126^{* * *} \\ \text { LP French }-4^{\text {th }} \text { level } & 0.081^{* * *} & -0.208^{* * *} & -0.272^{* * *} \\ \text { LP French }- \text { French } & -0.125^{* * *} & -0.034^{* * *} & 0.002 \\ & & & \\ \text { Immigrant in RoC } & & & -0.141^{* * *} \\ \text { LP French - None } & -0.030^{* * *} & -0.067^{* * *} & -0.154 * * * \\ \text { LP French }-1^{\text {st }} \text { level } & 0.070^{* * *} & -0.083^{* * *} & -0.186^{* * *} \\ \text { LP French }-3^{\text {rd }} \text { level } & 0.039 * * * & 0.093^{* * *} & -0.331^{* * *} \\ \text { LP French }-4^{\text {th }} \text { level } & 0.227^{* * *} & -0.223^{* * *} & -0.063^{* * *} \\ \text { LP French }- \text { French } & -0.016 & -0.095^{* * *} & 1,559,075 \\ \text { Observations } & 1,559,075 & 1,559,075 & \end{array}$

Using LP to English

\section{Quebec}

\section{Immigrant in Quebec}

\section{LP English - None}

LP English - $1^{\text {st }}$ level

LP English - $2^{\text {nd }}$ level

LP English - $3^{\text {rd }}$ level

LP English - English

\section{Immigrant in RoC}

LP English - None

LP English - $1^{\text {st }}$ level

LP English - $2^{\text {nd }}$ level

LP English - $3^{\text {rd }}$ level

LP English - English
Strength

$0.011^{* * *}$

$0.026 * * *$

$0.093^{* * *}$

$-0.113$

$-0.012$

$-0.114^{* * *}$
$0.071 * * *$
$0.258^{* * *}$
$-0.001$
0.002
$-0.073^{* * *}$

$1,559,075$

\section{Analytical}

$-0.076^{* * *}$

Social

$-0.062 * * *$

$\begin{array}{cc}-0.149^{* * *} & -0.202^{* * *} \\ -0.203^{* * *} & -0.278^{* * *} \\ 0.011 & 0.024 \\ -0.121^{* * *} & -0.135^{* * *} \\ 0.074 * * * & 0.129 * * *\end{array}$

$\begin{array}{cc}-0.178^{* * *} & -0.277^{* * *} \\ -0.275^{* * *} & -0.401^{* * *} \\ 0.022 & -0.078^{* * *} \\ -0.021^{* * *} & -0.104^{* * *} \\ 0.067^{* * *} & 0.045^{* * *} \\ 1,559,075 & 1,559,075\end{array}$

Regressions include controls for marital status, experience, experience squared, education, location, GDP per capita at country of origin, and survey year. Men are aged 18 to 60 . Immigrants are adults at arrival. RoC stands for Rest of country.

$(* * *, * *, *)$ indicates the coefficient is significantly different from 0 at 1,5 and $10 \%$ level respectively 
Figure 1. Distribution of job-required skills by immigrant status
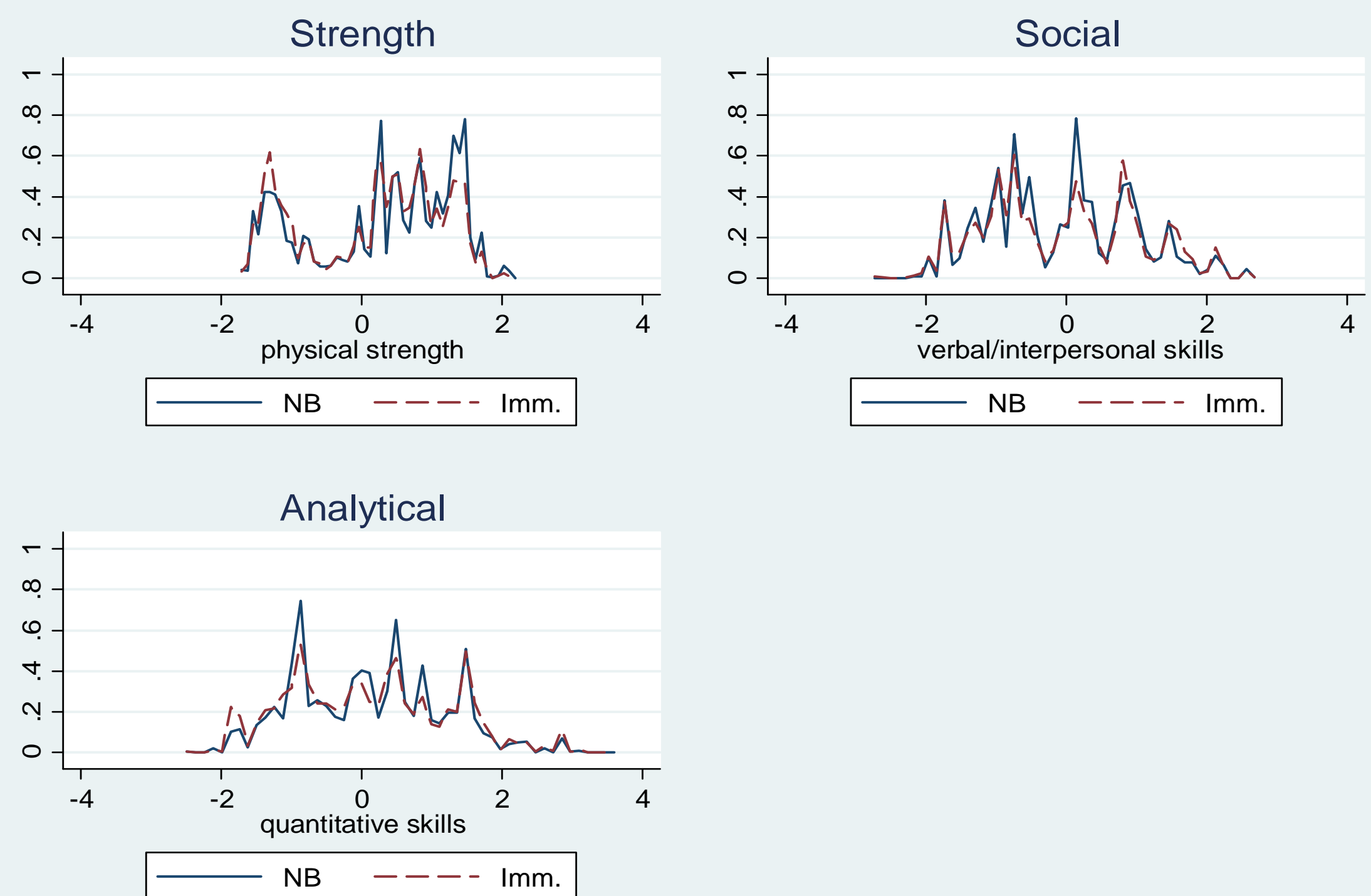
Figure 2. Predicted wages of immigrants in jobs requiring different skills ${ }^{(1)}$ relative to average worker (wage $=0$ )

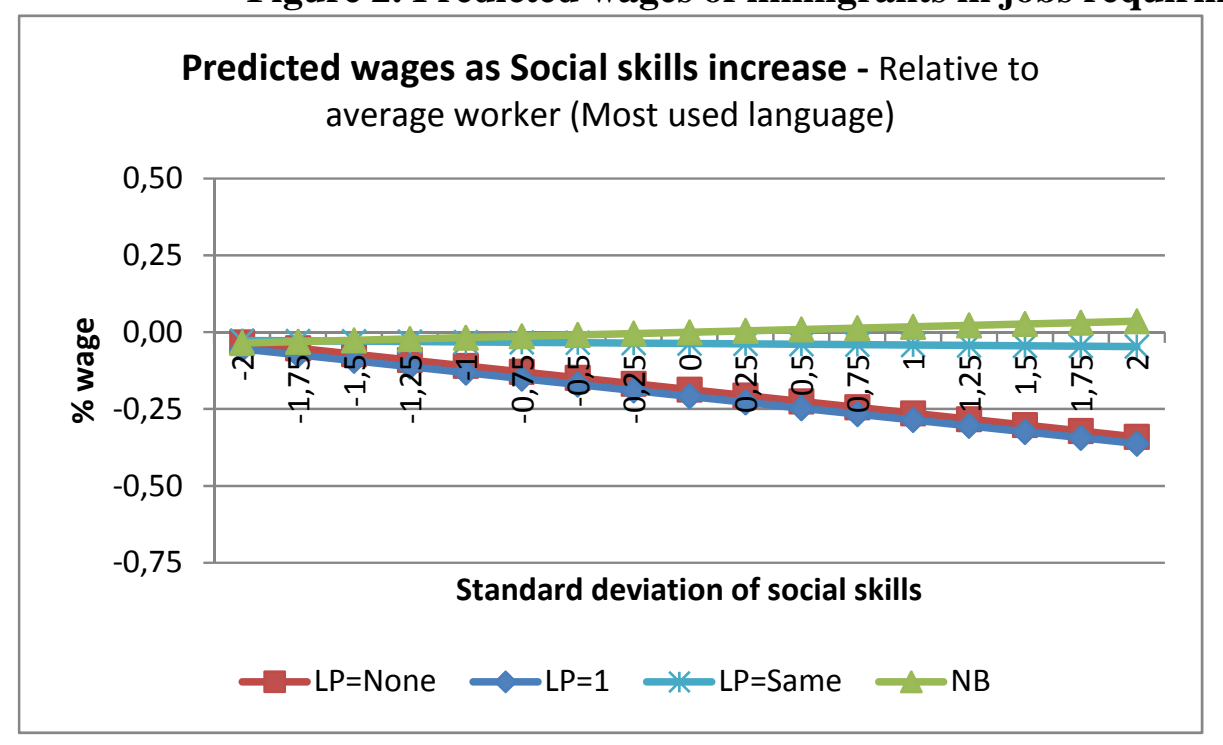

Predicted wages as Analytical skills increase - Relative to average worker (Most used language)

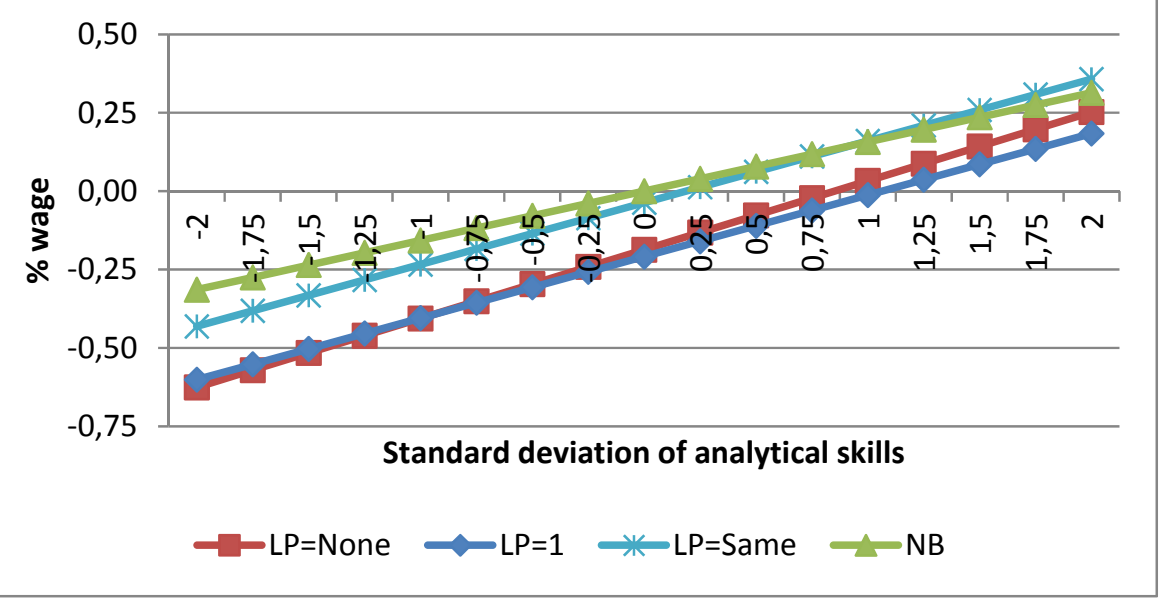

Figure 3. Immigrants’ wage assimilation by Linguistic Proximity and arrival cohort (LP)
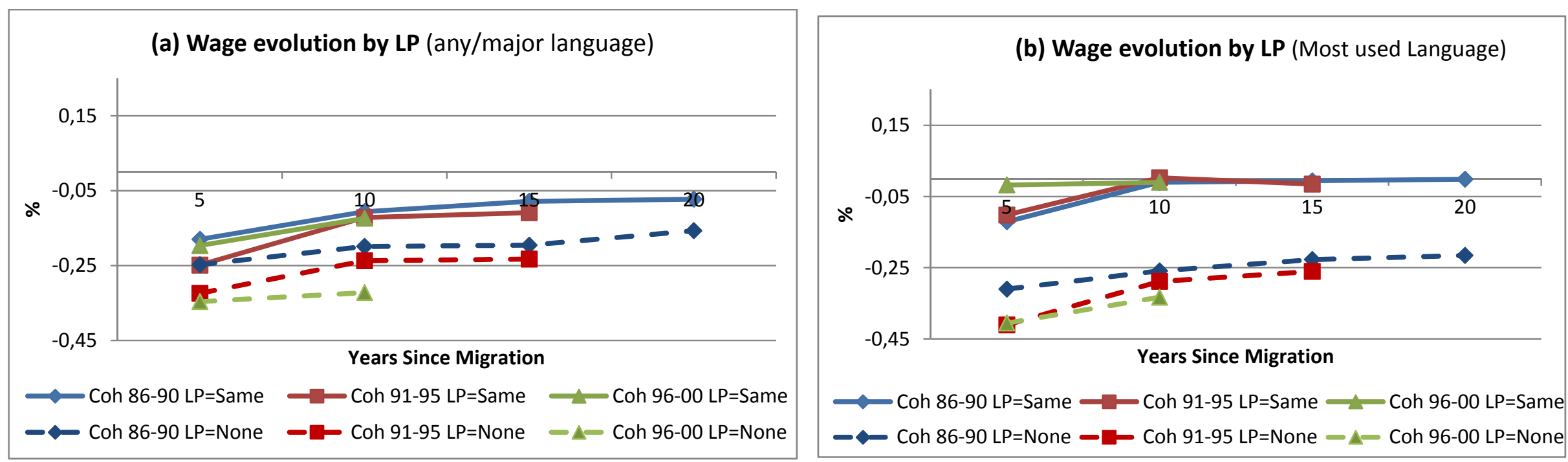

(1) $L P=1$ indicates language at origin and destination share one branch of linguistic tree. 
Figure 4. Evolution of job-required skills by Linguistic Proximity and arrival cohort (Most used language)
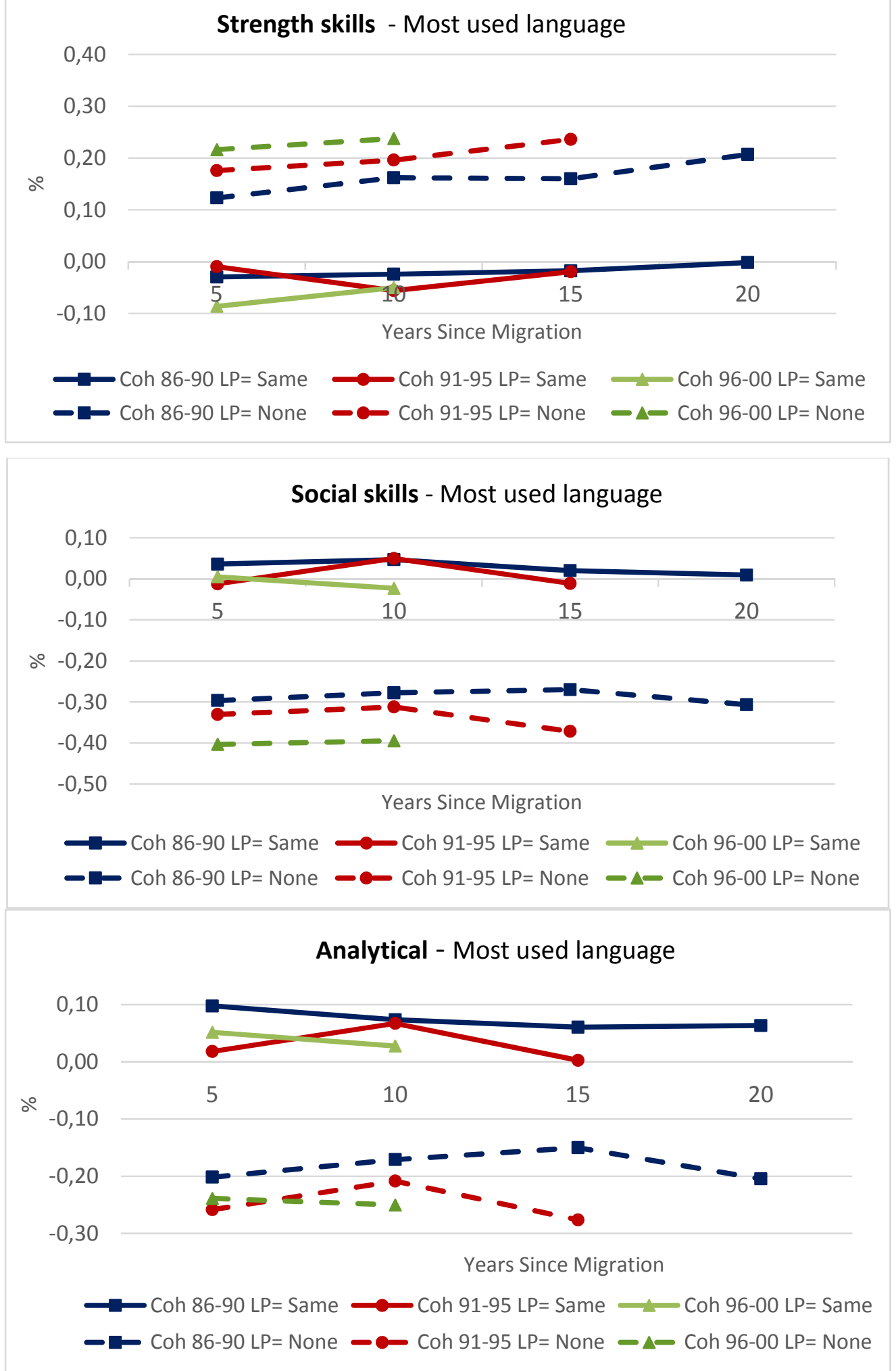

Note: Coefficients on cohort time effects. Regression also include marital status, experience, experience squared, education, location, area of origin indicators, GDP per capita at country of origin and survey year. 
Figure 5. Evolution of job-required skills for university educated immigrants.

By Linguistic Proximity and arrival cohort (Most used language)
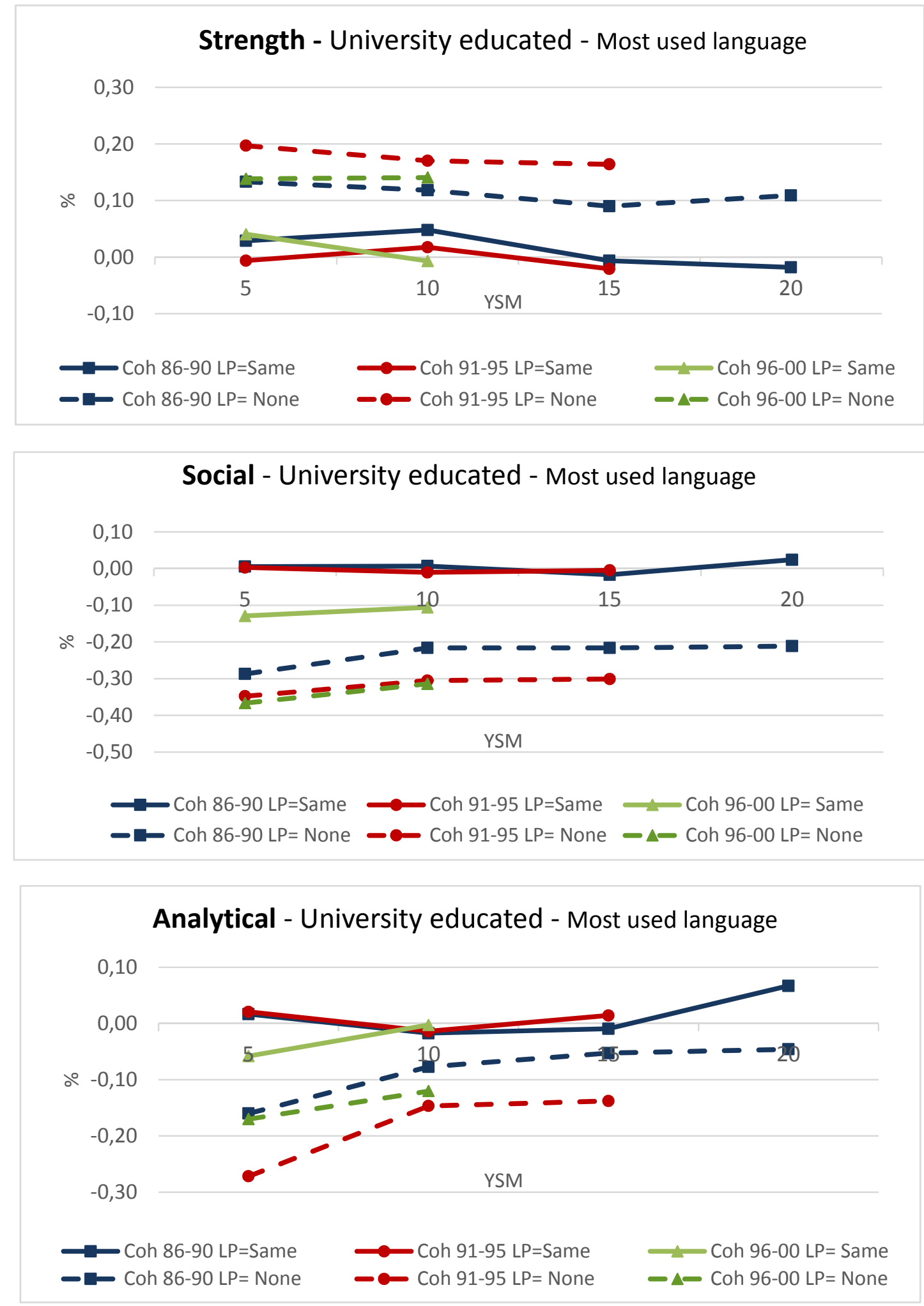
Appendix

Table 1A. Weekly wages of University-educated immigrant men

\begin{tabular}{|c|c|c|c|c|c|c|c|}
\hline & & \multicolumn{3}{|c|}{ Any Official/Major Language } & \multicolumn{3}{|c|}{ Most used language } \\
\hline & & $(1)$ & (2) & (3) & (4) & (5) & (6) \\
\hline \multirow[t]{3}{*}{ Skill index } & Social & $0.06 * * *$ & $0.06 * * *$ & $0.06^{* * *}$ & $0.06^{* * *}$ & $0.06^{* * *}$ & $0.06^{* * *}$ \\
\hline & Strength & $-0.06 * * *$ & $-0.06 * * *$ & $-0.06 * * *$ & $-0.06 * * *$ & $-0.06 * * *$ & $-0.06 * * *$ \\
\hline & Analytical & $0.19 * * *$ & $0.19 * * *$ & $0.19^{* * *}$ & $0.19 * * *$ & $0.19 * * *$ & $0.19 * * *$ \\
\hline \multirow{6}{*}{ LP indicators } & None & $-0.27 * * *$ & $-0.21 * * *$ & & $-0.31^{* * *}$ & $-0.28 * * *$ & \\
\hline & 1st Level & $-0.25^{* * *}$ & $-0.27^{* * *}$ & & $-0.27^{* * *}$ & $-0.24^{* * *}$ & \\
\hline & 2nd Level & -0.07 & -0.01 & & 0.002 & 0.003 & \\
\hline & 3rd Level & $-0.17^{* * *}$ & $-0.24 * * *$ & & $-0.13^{* * *}$ & $-0.13^{* * *}$ & \\
\hline & 4th Level & $-0.22 * * *$ & $-0.11 * * *$ & & & & \\
\hline & $\begin{array}{l}\text { Same } \\
\text { Language }\end{array}$ & $-0.12 * * *$ & $-0.05^{* * *}$ & & $-0.02 * * *$ & $-0.03^{* * *}$ & \\
\hline Immigrant & & & & $-0.11^{* * *}$ & & & $-0.01 * * *$ \\
\hline Levenshtein & & & & $-0.001 * * *$ & & & $-0.003 * * *$ \\
\hline POB control & & - & Yes & - & - & Yes & \\
\hline \multicolumn{8}{|c|}{$\begin{array}{l}\text { All regressions include controls for marital status, experience, experience squared, education, job-skills, } \\
\text { location, region of origin (omitted group is US/Europe), GDP per capita at country of origin and survey year. } \\
\text { Individuals are } 18 \text { to } 60 \text { years of age. Immigrants are adults at arrival. }\end{array}$} \\
\hline \multicolumn{8}{|c|}{$\begin{array}{l}\text { The first three columns (any language) show coefficients if linguistic proximity is measured by proximity } \\
\text { between any official or major language at origin and at destination (English or French). The last three columns } \\
\text { (most used language) show coefficients if linguistic proximity is measured by proximity between the most } \\
\text { commonly used language at origin and destination (English). }\end{array}$} \\
\hline
\end{tabular}


Table 2A. Effect of Linguistic Proximity and Skills on Male immigrant wages (relative to natives)

LP Any/Major

Social

Strength

Analytical

LP-none

LP-1 $1^{\text {st }}$

LP- $2^{\text {nd }}$

LP-3 ${ }^{\text {rd }}$

LP-4 $4^{\text {th }}$

LP-same

LP-None * Social

LP- ${ }^{\text {st }} *$ Social

LP- ${ }^{\text {nd }} *$ Social

LP-3 ${ }^{\text {rd }} *$ Social

LP-4 ${ }^{\text {th }} *$ Social

LP-same * Social

LP-None * Strength

LP- $1^{\text {st }} *$ Strength

LP- $2^{\text {nd }} *$ Strength

LP- $3^{\text {rd }} *$ Strength

LP- $4^{\text {th }} *$ Strength

LP-same * Strength

LP-None * Analytical

LP- ${ }^{\text {st }} *$ Analytical

LP-2 ${ }^{\text {nd }} *$ Analytical

LP- ${ }^{\text {rd }} *$ Analytical

LP-4 ${ }^{\text {th }} *$ Analytical

LP-same * Analytical
$0.02 * * *$

$-0.09 * * *$

$0.16^{* * *}$

$-0.18 * * *$

$-0.29 * * *$

0.01

$-0.23 * * *$

$-0.08 * * *$

$-0.06 * * *$

$-0.14 * * *$

$-0.08 * * *$

$-0.04$

$0.08 * * *$

$-0.14 * * *$

$-0.04 * * *$

$-0.02 * *$

0.00

$-0.04$

0.03

$0.04^{* * *}$

$0.06 * * *$

$0.07 * * *$

$0.02 * * *$

0.00

$-0.06 * * *$

$0.08 * * *$

$0.04 * * *$
LP Most Used

$0.02 * * *$

$-0.09 * * *$

$0.16^{* * *}$

$-0.19 * * *$

$-0.21 * * *$

$-0.02$

$-0.15^{* * *}$

$-0.04 * * *$

$-0.09 * * *$

$-0.09 * * *$

$-0.02$

$0.12 * * *$

$-0.02 * * *$

$0.03^{* * *}$

$0.07 * * *$

$-0.05$

$0.06 * * *$

$0.02^{* *}$

$0.06 * * *$

$0.04 * * *$

0.01

$-0.07 * * *$

$0.04 * * *$

The first column shows the coefficients from equation (4) when linguistic proximity is measured using proximity between any official or major languages at origin and English/French. Column (II) uses proximity between the most commonly used language at origin and English

Both regressions include controls for marital status, experience, experience squared, education, the rest of the job-skills interacted with linguistic proximity, location, area of origin indicators (the omitted group is US/Europe), GDP per capita at country of origin and survey year. Individuals are 18 to 60 years old. Immigrants are adults at arrival. Regressions have 1,353,560 observations

$(* * *, * *, *)$ indicates the coefficient is significantly different from 0 at 1,5 and $10 \%$ respectively 
Table 3A. Effect of language on skills required by jobs

\begin{tabular}{|c|c|c|c|c|c|c|c|c|}
\hline \multicolumn{5}{|c|}{ Any official/major language ${ }^{(1)}$} & \multicolumn{4}{|c|}{ Most used language (3) } \\
\hline LP & Strength & Social & Analytical & Complexity & Strength & Social & Analytical & Complexity \\
\hline \multirow[t]{2}{*}{ None } & 0.05 & -0.08 & 0.02 & -0.03 & 0.15 & -0.26 & -0.13 & -0.03 \\
\hline & $(0.00)$ & $(0.00)$ & $(0.00)$ & $(0.00)$ & $(0.00)$ & $(0.00)$ & $(0.00)$ & $(0.00)$ \\
\hline \multirow[t]{2}{*}{ 1st Level } & 0.14 & -0.27 & -0.17 & -0.03 & 0.22 & -0.35 & -0.23 & -0.04 \\
\hline & $(0.00)$ & $(0.00)$ & $(0.00)$ & $(0.00)$ & $(0.00)$ & $(0.00)$ & $(0.00)$ & $(0.00)$ \\
\hline \multirow[t]{2}{*}{ 2nd Level } & 0.07 & -0.12 & 0.01 & 0.01 & 0.01 & -0.07 & 0.05 & 0.00 \\
\hline & $(0.00)$ & $(0.00)$ & $(0.54)$ & $(0.86)$ & (0.70) & $(0.00)$ & $(0.00)$ & $(0.89)$ \\
\hline \multirow[t]{2}{*}{ 3rd Level } & 0.02 & -0.13 & 0.01 & -0.02 & 0.01 & -0.10 & -0.01 & -0.02 \\
\hline & $(0.01)$ & $(0.00)$ & $(0.35)$ & $(0.00)$ & $(0.40)$ & $(0.00)$ & $(0.40)$ & $(0.05)$ \\
\hline \multirow[t]{2}{*}{ 4th Level } & 0.08 & -0.16 & -0.06 & -0.02 & & & & \\
\hline & $(0.00)$ & $(0.00)$ & $(0.00)$ & $(0.00)$ & & & & \\
\hline \multicolumn{9}{|l|}{ Same } \\
\hline \multirow[t]{2}{*}{ Language } & 0.07 & -0.10 & -0.05 & -0.03 & -0.07 & 0.06 & 0.09 & -0.02 \\
\hline & $(0.00)$ & $(0.00)$ & $(0.00)$ & $(0.00)$ & $(0.00)$ & $(0.00)$ & $(0.00)$ & $(0.00)$ \\
\hline \multicolumn{9}{|c|}{$\begin{array}{l}\text { All regressions include controls for marital status, experience, experience squared, education, location, region of origin (omitted } \\
\text { group is US/Europe), GDP per capita at country of origin and survey year. Individuals are } 18 \text { to } 60 \text { years old. Immigrants are adults } \\
\text { at arrival. }\end{array}$} \\
\hline \multicolumn{9}{|c|}{$\begin{array}{l}\text { The first three columns (any official/major language) show coefficients if linguistic proximity is measured by proximity between } \\
\text { any official or two most widely-spoken languages at origin and official language at destination (English or French). The last three } \\
\text { columns (most used language) show coefficients if linguistic proximity is measured by proximity between the most commonly } \\
\text { used language at origin and destination (English). }\end{array}$} \\
\hline \multicolumn{9}{|c|}{$(* * *, * *, *)$ indicates the coefficient is significant at $1 \%, 5 \%$ or $10 \%$ respectively } \\
\hline
\end{tabular}


Table 4A. Average skills required in jobs held by immigrants. By linguistic proximity

\begin{tabular}{lccc} 
& Social & Analytical & Strength \\
\cline { 2 - 4 } Native born & -0.09 & 0.04 & 0.29 \\
Immigrant & -0.09 & 0.12 & 0.16
\end{tabular}

LP

None

1st Level

2nd Level

3rd Level

4th Level

Same Language

None

1st Level

2nd Level

3rd Level

4th Level

Same Language
Any Official/ Major language

$-0.08$

0.16

0.05

0.33

0.39

$-0.12$

0.05

0.06

0.25

0.23

0.12

0.38

0.28

\section{Most used language}

$-0.08$

0.13

0.08

$-0.32$

$-0.06$

0.36

0.16

0.39

0.13

0.08

0.30

0.17

$-0.08$

0.05

0.29

Table 4B. Correlation of Skills employed in Jobs

\begin{tabular}{lccccc} 
& Analytical & Social & Visual & Motor & Strength \\
\cline { 2 - 6 } Analytical & 1.00 & & & & \\
Social & 0.88 & 1.00 & & & \\
Visual & -0.30 & -0.38 & 1.00 & & \\
Motor & -0.49 & -0.67 & 0.78 & 1.00 & \\
Strength & -0.65 & -0.75 & 0.67 & 0.89 & 1.00
\end{tabular}


Table 5: Selection Grid before and after IRPA (2002)

Selection grid for skilled workers (maximum number of points)

\begin{tabular}{|c|c|c|c|c|c|}
\hline & \multicolumn{3}{|c|}{ Before IRPA } & \multicolumn{2}{|c|}{ After IRPA } \\
\hline & Canada & $\begin{array}{c}\text { Quebec } \\
1979\end{array}$ & $\begin{array}{l}\text { Quebec } \\
1995\end{array}$ & Quebec & Canada \\
\hline Education & 34 & 21 & 17 & 11 & 25 \\
\hline Experience & 8 & 10 & 10 & 10 & 21 \\
\hline Age & 10 & 10 & 10 & 10 & 10 \\
\hline Language & 15 & 12 & 23 & $24 *$ & $24 *$ \\
\hline Family ties & 5 & 5 & & & \\
\hline Spousal characteristics & 10 & & 17 & 5 & \\
\hline Children & & 4 & 8 & & \\
\hline Offer of employment & 10 & 20 & 15 & 15 & 10 \\
\hline Adaptability & 10 & 23 & 14 & & 10 \\
\hline Total & 112 & 104 & 114 & 75 & 105 \\
\hline Passing score & $63 \%$ & $48 \%$ & $52 \%$ & $77 \%$ & $71 \%$ \\
\hline \multicolumn{6}{|c|}{$\begin{array}{l}\text { * In Quebec } 8 \text { of the } 16 \text { points are awarded to English knowledge. In the RoC } 6 \text { of the } \\
24 \text { points are awarded to a Second language }\end{array}$} \\
\hline \multicolumn{6}{|c|}{$\begin{array}{l}\text { Source: Author's compilation. Data from the federal program comes from Beign et al } \\
\text { (2010), data for Quebec from Houle (2014) }\end{array}$} \\
\hline
\end{tabular}

